\title{
The relation between the wage, job-related training and the quality of the match between occupations and the types of education
}

Citation for published version (APA):

van Eijs, P. W. L. J., \& Heijke, J. A. M. (1996). The relation between the wage, job-related training and the quality of the match between occupations and the types of education. Researchcentrum voor Onderwijs en Arbeidsmarkt, Faculteit der Economische Wetenschappen. ROA Research Memoranda No. 6E https://doi.org/10.26481/umaror.199606E

Document status and date:

Published: 01/01/1996

DOI:

10.26481/umaror.199606E

Document Version:

Publisher's PDF, also known as Version of record

Please check the document version of this publication:

- A submitted manuscript is the version of the article upon submission and before peer-review. There can be important differences between the submitted version and the official published version of record.

People interested in the research are advised to contact the author for the final version of the publication, or visit the DOI to the publisher's website.

- The final author version and the galley proof are versions of the publication after peer review.

- The final published version features the final layout of the paper including the volume, issue and page numbers.

Link to publication

\footnotetext{
General rights rights.

- You may freely distribute the URL identifying the publication in the public portal. please follow below link for the End User Agreement:

www.umlib.nl/taverne-license

Take down policy

If you believe that this document breaches copyright please contact us at:

repository@maastrichtuniversity.nl

providing details and we will investigate your claim.
}

Copyright and moral rights for the publications made accessible in the public portal are retained by the authors and/or other copyright owners and it is a condition of accessing publications that users recognise and abide by the legal requirements associated with these

- Users may download and print one copy of any publication from the public portal for the purpose of private study or research.

- You may not further distribute the material or use it for any profit-making activity or commercial gain

If the publication is distributed under the terms of Article $25 \mathrm{fa}$ of the Dutch Copyright Act, indicated by the "Taverne" license above, 


\section{The Relation between the Wage, Job-related Training and the Quality of the Match between Occupations and Types of Education}

ROA-RM-1996/6E

Patrick van Eijs and Hans Heijke

Research Centre for Education and the Labour Market

Faculty of Economics and Business Administration

University of Limburg

Maastricht, June 1996 
ISBN 90-5321-190-X 


\section{Contents}

Abstract

1 Introduction

2 The relation between the quality of the match, earnings and training 6

$\begin{array}{ll}2.1 \text { Introduction } & 6\end{array}$

2.2 The theoretical framework 6

2.3 The earnings model 11

3 Measuring the quality of the match 14

3.1 Introduction $\quad 14$

3.2 The educational level and the initial wage 14

3.3 The subject of study and the initial wage $\quad 21$

4 Towards an empirical model 23

4.1 Introduction 23

4.2 Determinants of the wage 23

4.3 An empirical model of the earnings function 25

4.4 An empirical model of the training cost function 27

5 The data 28

5.1 The data set 28

5.2 Some descriptive statistics 29

6 Empirical analysis 33

6.1 Introduction 33

6.2 Testing three alternative earnings models 33

6.3 The earnings function by occupational level 34

6.4 The earnings function by occupational field 39

6.5 The training cost function 42

7 Conclusions 44

$\begin{array}{ll}\text { References } & 46\end{array}$

Appendix 1 Derivation of the Taylor approximations 49 
Appendix 3 Tenure-earnings profiles by occupational field (net monthly wages in f.t.e. in dutch guilders) 


\begin{abstract}
The aim of the paper is twofold. In the first place, to find an explanation for the mismatch phenomena which can be found on the labour market by emphasising the nontransparency of the labour market. In the second place, to derive an objective mismatch measure, which enables to investigate the quality of the match between occupations and types of education and to find that particular type of education which has a comparative advantage in the occupation concerned. The result is a theoretical model in which concave earnings-training profiles are derived. Initial wages indicate the quality of the match. Training is used to decrease the mismatch between acquired and required skills.
\end{abstract}

By estimating earnings function by occupational level and occupational field the theoretical framework has been tested empirically. The hypothesis that the earnings-tenure profile is concave can be confirmed by the estimates. Furthermore, the estimates of the mismatch measure yield attractive results, especially concerning the quality of the match between occupational and educational levels. Finally, estimating a training function confirms the hypothesis that training efforts are positively related to the degree of mismatch. So, it may be concluded that the approach which has been developed in this paper yields a useful mismatch measure. 


\section{Introduction}

Estimating the earnings function and explaining differences in earnings are important issues in economic literature. For a great deal, research on these topics is based on the human capital theory. The human capital theory focuses on supply characteristics. Ability, education and training are the determinants of the amount of human capital an individual possesses and, as a result, of an individual's productivity in a job. Embedded in a neoclassical framework, the human capital theory implies that a higher ability, more education and more training do not only result in a higher productivity level, but also yield higher earnings.

Within this human capital tradition, Mincer's (1974) earnings function plays an important role (Willis, 1986). Mincer's earnings function assumes earnings to be determined by the amount of formal education (often in years) and experience. Experience is assumed to have a positive effect on earnings, because, during their career, individuals increase their amount of human capital by means of on-the-job and formal vocational training. The experience-earnings profile is assumed to be concave, reflecting that age has a negative effect on the amount of additional training, because of the negative effect of age on the rate of return on training.

The human capital theory implies that earnings are merely determined by supply characteristics. The productivity level, and hence earnings, is not influenced by job characteristics. This feature of the human capital theory has caused serious criticism. In Thurow's (1975) job competition model the productivity and earnings are merely determined by job characteristics. This implies that individual characteristics play no role in a worker's productivity in a particular job. They do play a role, however, in the selection of workers for a job. More human capital implies a better trainability, that is lower training costs in order to achieve the required productivity level in the job. In other words, more human capital (that is, more education) improves the opportunities to find a well-paid job.

While the human capital theory focuses on supply characteristics and the job competition model focuses on job characteristics to explain earnings, job matching theory concentrates on both. ${ }^{1}$ On the one hand, the demand side of the labour market is assumed to consist of jobs with different skill requirements. On the other hand, the supply side consists of individuals who have acquired skills by means of education and training. The job matching theory states that the quality of the match (that is, the degree of alignment between required and acquired skills) determines the productivity level and earnings in a job. The better the match, the higher the productivity level is and the higher earnings are. As a

1. Important contributions to the development of the job matching theory have, for example, been made by Tinbergen (1956), Jovanovic (1979) and Hartog (1992). An overview can be found in Sattinger (1993). 
result, the allocation of workers over jobs becomes very important. If a worker lacks the required skills, his productivity will be lower than if he is employed in a job in which his skills are perfectly in alignment with the requirements. Furthermore, this worker achieves a lower productivity level than a worker with the accurate skills for the job concerned. In order to describe the optimal allocation of workers over jobs according to the job matching theory, the concept of comparative advantage has been introduced (Sattinger, 1975). The allocation is optimal if a worker is allocated to a job in which he performs relatively the best compared to the other workers.

Although both employers and workers benefit from a perfect match between required and acquired skills, mismatch is a phenomenon which can often be observed in practice. With regard to the Dutch labour market, for example, Gelderblom, 't Hoen and De Koning (1994) show that 13 percent of the workers are employed in a job which is not in alignment with the subject of study, 4 percent works above and 12 percent below their educational level. Van de Loo, Hoevenberg en Van der Velden (1995) show that 19 percent of the employed school-leavers of Higher Vocational Education who graduated in 1993 consider the alignment between required and acquired skills to be insufficient. Finally, Groot and Maassen-van den Brink (1996) state that in 1995 about 12 percent of the labour force is undereducated, while even more than 24 percent are overeducated.

In the job matching literature attention has been paid to the consequences of a mismatch between required and acquired skills on the rate of return on education. These studies focus on the effect of the educational level. Cohn and Khan (1995) give an overview of these studies. They conclude that the rate of return on years of under- and overeducation is much lower than the rate of return on years of required education. ${ }^{2}$ This implies that, in a particular job, the undereducated earn much less, while the overeducated earn only slightly more than the workers whose educational level is in alignment with the requirements. These findings illustrate the concept of comparative advantage. Although overeducated workers, for example, earn more than adequately educated workers, they would have earned more in a job in which the educational requirements are higher and more in alignment with the skills they offer.

This paper links up with the job matching literature in general and the studies considering the earnings effect of a mismatch mentioned above in particular. The aim of the paper is twofold. In the first place, to find an explanation for the mismatch phenomena mentioned above by investigating the consequences of the nontransparency of the labour market for the recruitment policy of firms. Secondly, to find a measure for the quality of the match between occupations and types of education.

2. In Hartog and Oosterbeek (1988), Van Smoorenburg and Van der Velden (1995) and Oosterbeek and Webbink (1996) similar results can be found for the Dutch labour market. 
The first aim is to find an explanation for the occurrence of mismatches. If the labour market functions perfectly, an optimal allocation of heterogeneous workers with regard to their educational background over heterogeneous jobs (occupations) can be the only result of the decisions of welfare-maximising agents. This implies that, if it is assumed that agents maximise welfare, a mismatch indicates an imperfect functioning of the market. This paper focuses on the nontransparency of the labour market as an explanation for a nonoptimal allocation with regard to the skills acquired and required. If the labour market is not transparent, employers have to search for workers whose skills (educational background) are in alignment with the requirements for the job (occupation) concerned and who are able to achieve the optimal productivity level (that is, the profit-maximising productivity level). This search process yields costs. ${ }^{3}$ However, if workers lack skills, they are not able to achieve the productivity level the 'perfectly matching worker' achieves. In this paper it is assumed that employers train their workers in order to bring undereducated workers on the optimal productivity level in the occupation concerned. This implies that the costs to find the 'perfectly matching worker' with the perfect educational background may be higher than the training costs to bring the 'imperfectly matching worker' on the optimal productivity level. ${ }^{4}$ In other words, the cost-minimising employer may decide to recruit a worker who does not have the required skills and to train this worker in order to enable him to achieve the optimal productivity level. ${ }^{5}$

This explanation for the occurrence of mismatches implies that the quality of the match improves with job tenure. The longer a worker is employed, the more job-related training he has obtained and the higher his productivity level will be. ${ }^{6}$ It is reasonable to assume that this productivity gain is reflected in the earnings. In this paper an earnings model based on Mincer (1974) is introduced in a job-related context in order to describe the impact of jobrelated training on the productivity and the earnings in an occupation. This model yields tenure-earnings profiles which are linked with both occupational and educational background characteristics. In other words, elements of the human capital theory are introduced in a job matching context in order to describe the improving quality of the match between the required skills in an occupation and the skills which a worker, with a particular educational background has acquired, over time. Furthermore, note that in the long run (that is, if the mismatches have been eliminated by means of training), the model described

3. Howitt (1988) and Layard et al. (1991) describe search models, in which the search costs are an increasing function of the tension on the labour market.

4. To be precise, an imperfect match yields also costs caused by the productivity loss, as long as the worker is not able to achieve the desired productivity level.

5. Note that this explanation implies that formal education and job-related training are substitutes.

6. The model presented in this paper differs from other matching models. Most matching models assume, following Jovanovic (1979), that the quality of the match improves with experience as a result of job mobility. In this paper job-related training yields a better match between the worker's skills and the required skills. 
shows much resemblance with Thurow's (1975) job competition model. Training is used to bring a worker on the optimal productivity level which is assumed to be linked with the job. In order to find evidence for the explanation for the occurrence of mismatches given in this paper, the link between training efforts and the quality of the match is also investigated empirically.

In the short run, however, the quality of the match determines the productivity level and, therefore, earnings. This brings us to the second aim of the paper. Most of the studies dealing with the effect of under- and overeducation on the rate of return on education mentioned above suggest that the undereducated earn much less, while the overeducated earn only slightly more than workers whose educational level is in alignment with the requirements (Cohn and Khan, 1995). A crucial element of these studies is the way in which the 'optimal' level and, consequently, under- and overeducation are defined. Several methods can be distinguished. Both Hartog and Oosterbeek (1988) and Sloane et al. (1995) mention two methods. The first method consists of the evaluation of jobs by job analysts. The second method extracts information from the individual worker by asking to specify the type of education required for adequate performance in the job. A third method uses data on the educational background of workers employed in a particular occupation. Cohn and Khan (1995), for example, use the worker's mean educational level as a measure for the optimal level. These methods reveal an important weakness of these studies; the optimal level, under - and overeducation are defined by means of subjective or indirect methods, which focus on determining the 'optimal' level.

As a result, these rate of return studies are restricted. First, the quality of the match can not be determined objectively. Second, the methods which are used to determine the optimal educational level and over- and undereducation imply that they are not able to measure the degree of over- and undereducation. Therefore, often this problem is avoided by making the assumption that the rate of return on education is not related to the degree of under- or overeducation. An overview of these studies can be found in Cohn and Khan (1995). Studies in which the rate of return indeed is related to the degree of over- and undereducation (for example Sloane et al., 1995), the degree of over- and undereducation is predetermined by means of a subjective or indirect method mentioned above.

Freeman (1976) has stated that a decline in earnings for workers with a particular educational background indicates that more workers are overeducated compared to the requirements in their jobs. This implies that Freeman has used earnings as a measure for overeducation. This idea is also used in this paper. A model is formulated which enables to define a measure for the quality of the match between occupations and types of education. This model heavily relies on the estimates of the rate of return studies mentioned before. The line of reasoning is reversed, however. In the rate of return studies mentioned above, the link between the quality of the match and the rate of return, which is made in the job matching theory, has been used to determine the rate of return, given the (exogenously 
determined) quality of the match. In this paper this link is used to determine the quality of the match. In this context, the initial wage (that is, the wage earned if a worker has no experience in the occupation concerned) is used as a measure for the rate of return on the worker's type of education in the occupation concerned. Estimates for this initial wage are obtained by estimating the tenure-earnings profile. With the asymmetric effect of underand overeducation on earnings mentioned by Cohn and Khan (1995) in mind, this initial wage yields a monetary measure for the quality of the match between the type of education and the occupation concerned. Furthermore, this approach yields the opportunity to introduce into the analysis both the educational and the occupational level on the one hand and the subject of types of education and the occupational field on the other hand.

The structure of the remainder of this paper is as follows. In section 2 the theoretical earnings model is described. Starting-point for this model is the assumption that the labour market is not transparent. The model describes the relation between the quality of the match, earnings and the training efforts. Furthermore, a comparison is made between the earnings model on the one hand and the job matching theory, the human capital theory and the job competition model on the other hand. The earnings model yields a monetary measure (that is, a measure based on earnings) for the quality of the match between occupations and types of education. In section 3 a model dealing with the link between the quality of the match between types of educations and occupations, that is the degree of alignment between acquired and required skills and the monetary measure is formulated. Section 4 transforms the theoretical model into an empirical model. In section 5 a short description is given of the data used in the empirical analyses. In section 6 the results of the estimations are presented and discussed. In the first place, we compare, following Hartog (1985), the performance of the earnings model based on the assumption that both occupational and educational background characteristics determine earnings (job matching theory) with the performance of the more restricted models. These more restricted models include, respectively, occupational (job competition model) and educational background characteristics only (human capital theory). Secondly, the estimates of the tenure-earnings profiles by occupational level are presented. These estimates yield measures for the degree of under- and overeducation of workers. Thirdly, this profile is estimated by occupational field. By means of these estimation the subject of study is introduced in the analysis. Finally, the link between training efforts and the quality of the match is discussed using the estimation results of the earnings function by occupational level. Investigating this link empirically enables to underpin the earnings model of section 2 . In section 7 the paper is rounded off with some concluding remarks. 


\section{The relation between the quality of the match, earnings and training}

\subsection{Introduction}

In section 1 it is stated that it is possible to explain the occurrence of mismatches between required skills in a job and the acquired skills by a worker by means of introducing jobrelated training in a nontransparent labour market. This results in an earnings model in which the mismatch is a decreasing function of job tenure. In this section this model is formulated. First, attention is paid to the theoretical framework which describes the relation between the quality of the match, earnings and the training efforts. In the second place, an alternative interpretation of the earnings model, in terms of the human capital theory, the job competition model and the matching theory, is given. Finally, this framework is formalised in a model.

\subsection{The theoretical framework}

The starting-point for the analysis is the following production function describing the production technology of a price-taking and profit-maximising firm: ${ }^{7}$

$$
Q=q\left(L_{1}, L_{2}, \ldots, L_{j}, \ldots, L_{n}\right)
$$

in which $Q$ reflects the production volume and $L_{j}$ indicates the number of workers employed in occupation $j$. If the price of the commodity the firm produces is equal to $P$ and the wage $W_{j}$ is paid to the workers, according to the occupation they practise, the profit function $\pi$ of the firm looks as follows:

$\Pi=P Q-\sum_{j=1}^{n} W_{j} L_{j}$

Maximising profit yields the following occupational labour demand function:

$$
L_{j}=I_{j}\left(W_{1}, W_{2}, \ldots, W_{j}, \ldots, W_{n}, Q\right)
$$

The educational background of those employed by the firm in the various occupations plays no role in this model. This feature of the model implies that either the assumption is made that individuals are allocated to that occupation in which their skills can be used

7. Note that labour is assumed to be the only production factor. This assumption is made for reasons of simplicity. 
optimally or that individuals with a different educational background are perfect substitutes within an occupation. ${ }^{8}$

In this paper a model is formulated in which both assumptions are not valid. Dropping the assumption that individuals are perfect substitutes implies that the firm maximises profit by finding the perfectly matching workers for their jobs. However, in section 1 it was stated that in an imperfect labour market, recruiting workers whose skills are not in alignment with the requirements may be a profit-maximising strategy. In this paper we focus on the consequences of the nontransparency of the labour market for the recruitment policy of firms. Therefore, the assumption that workers are perfectly allocated over the various occupations is also dropped here. The focus is on explaining the occurrence of mismatches between the educational background of workers and the occupations in which they are employed on the one hand and on investigating the consequences of these mismatches on the other hand.

If the labour market is not transparent, finding the worker whose educational background is such that his skills are in alignment with the skills required in the occupation may not be an easy job. ${ }^{9}$ Searching for the perfectly matching worker yields costs, especially if the perfectly matching worker is hard to find. Howitt (1988) and Layard et al. (1991), for example, describe search models in which the search costs are an increasing function of the tension on the labour market. However, recruiting an imperfectly matching worker, who may be much easier to find, implies that training costs have to be made in order to tide over the gap between acquired and required skills. ${ }^{10}$ The profit-maximising firm aims to minimise the costs of recruiting and training a new worker. This can imply that an imperfect match may be cost-minimising for the firm; in that case the search costs which have to be made to find the perfectly matching worker are higher than the total of the search and training costs which have to be made to make the imperfectly matching worker suitable for his job. This implies also that education and training are substitutes. If the skills acquired by education are insufficient, on-the-job and formal job-related training can be used as an alternative.

8. By making the second assumption $L_{j}$ does not reflect the number of people employed in an occupation, but the perfect equivalent of that number.

9. It should be noted that the assumption is made that the nontransparency of the market does not reveal in an imperfect knowledge of the degree of alignment between types of education and occupations.

10. Recruiting an imperfectly matching worker yields another type of costs. Because the worker lacks the required skills there is a productivity loss. Within the job in which the worker is employed, this is not a problem because the wage is lower also. But the productivity loss has consequences within other occupations also. As a result, recruiting an imperfectly matching worker has spill-overs to other occupations. Although these costs may be an important incentive for firms to train new workers these spill-overs are not taken into account in this paper. The analysis is partial. 
The consequence of the fact that recruiting an imperfectly matching worker can be a costminimising strategy is that the equations (2.1) to (2.3) can be considered to be a long run model. If the assumption is made that a firm trains a new worker who lacks the skills required in order to make him as productive as the worker whose skills match perfectly, the equation (2.1) to (2.3) describe the profit-maximising long run labour demand by occupation.

In the short run, however, a mismatch results in a lower productivity. Training is needed to enable the new worker to achieve the optimal productivity level according to the long run model. As job tenure increases, productivity increases as a result of the training efforts. If the assumption is made that a worker is paid according to his productivity, figure 2.1 may be a good description of the effect of the quality of the match on the wage.

Figure 2.1

The quality of the match and the wage

Figure 2.1 shows that the wage $W_{i j}$ paid to a worker with educational background $i$ employed in occupation $j$ is an increasing function of job tenure $t$. The positive slope of the tenure-wage profile reflects the effect of job-related training on the quality of the match and on the productivity level. Figure 2.1 shows also that the tenure-wage profile is concave; the training efforts and, as a result, the wage gain, are assumed to be a decreasing function of job tenure. This is a well-known finding in studies dealing with estimating these profiles (Ehrenberg and Smith, 1994). In the context of this paper, the following explanation 
can be given for the concavity of the profile (Mincer, 1989). Training yields a productivity gain. The faster, the training is completed the longer a firm can benefit from a higher productivity and a worker can benefit from a higher wage. The longer the training which is required to improve the quality of the match is postponed, the higher the total productivity (and wage) loss due to the imperfect match will be. Therefore, there is an incentive for both firms and workers to concentrate the training efforts immediately after the recruitment. However, in order to enable a worker to benefit from learning-by-doing also, the training efforts will not take all at once. This results in a training pattern in which training efforts decrease with job tenure.

The tenure-wage profile of figure 2.1 may be described by the following earnings function:

$$
W_{i j, t}=W_{j}^{p}-M M_{i j} e^{-L A l_{i} t} \quad M M_{i j}, L A I_{i} \$ 0
$$

Equation (2.4) contains three parameters. First, $W_{j}^{p}$ which is the wage paid to the worker whose educational background matches perfectly with the skills required for occupation $j$. It is the wage which can also be found in the equations (2.2) and (2.3) of the long run model. The worker, whose educational background was not in alignment with the skills required, but who has been trained to achieve the same productivity level as the perfectly matching worker, also receives the wage $W_{j}^{p}$ in the long run.

In the second place, $M M_{i j}$ reflects the degree of mismatch between type of education $i$ and occupation $j$. If a new worker is recruited (that is, $t=0$ ), his wage $W_{i j, 0}$ is:

$$
W_{i j, 0}=W_{j}^{p}-M M_{i j}
$$

Equation (2.5) implies that $M M_{i j}$ measures the gap between the wage paid to the perfectly matching worker and the wage paid to a worker with educational background $i$ without experience in occupation $j W_{i j, 0}$. Therefore, it can be considered to be a monetary measure for the skills this worker lacks to make him suitable for occupation $j . M M_{i j}$ is a decreasing function of the quality of the match. The better the quality of the match, the lower $M M_{i j}$. Figure 2.2 shows two tenure-wage profiles. It shows that $M M_{a j}<M M_{b j}$; the quality of the match between type of education $a$ and occupation $j$ is better than the quality of the match between type of education $b$ and occupation $j$. Therefore, $W_{a j, 0}>W_{b j, 0}$; for workers employed in occupation $j$, the initial wage for the workers with education background $a$ is higher than for the workers with educational background $b$.

Finally, $L A I_{i}$ determines the degree of concavity of the tenure-wage profile. In the context of this paper, it measures the rapidity of the increase in productivity. In other words, the higher $L A I_{i}$, the faster the gap between acquired and required skills is closed. Therefore, in this paper $L A I_{i}$ is considered to be a learning ability index. It is a measure for a worker's 
learning ability. The higher the learning ability, the more effective on-the-job and formal job-related

Figure 2.2

Types of education and the quality of the match

training are and the higher the productivity gain of a particular amount of training will be. The

learning ability is assumed to be determined by the educational background $i .{ }^{11}$ Figure 2.3 shows two tenure-wage profiles. It shows that $L A I_{c}<L A l_{d}$; the learning ability of workers with educational background $c$ is lower than the learning ability of workers with educational background $d$.

The earnings function (2.4) can be related to the human capital theory, the job competition model and the job matching theory by distinguishing three stages in which the earnings function takes a different form. As stated before, if $t=0$, the earnings function looks as follows:

$$
W_{i j, 0}=W_{j}^{p}-M M_{i j}
$$

Equation (2.5) implies that the quality of the match determines the wage earned in occupation $j$. This implies that, if $t=0$, the earnings function fits in the job matching theory. Both worker and job characteristics are related to earnings. If the worker has some experience in

11. See section 5 for more details. 
the job (that is, if $0<t<4$ ), training increases productivity and, as a result, earnings. The earnings function looks as follows:

$$
W_{i j, t}=W_{j}^{p}-M M_{i j} e^{-L A l_{i} t}
$$

Figure 2.3

Types of education and learning ability

Equation (2.4) implies that supply characteristics (the worker's training efforts and learning ability) determine the increase in earnings. Therefore, if $0<t<4$, the earnings function fits in the human capital theory in a job-related context. Finally, in the long run (that is, if $t=4$ ), the earnings function looks as follows:

$$
W_{i j, 4}=W_{j}^{p}
$$

Equation (2.6) implies that, in the long run, job characteristics determine the wage. Therefore, if $t=4$, the earnings function fits in the job competition model.

\subsection{The earnings model}

In this subsection the theoretical framework describing the relation between the quality of the match, earnings and training efforts will be formalised in a model. The model presented 
here is a variant of Mincer's (1974) human capital earnings function. ${ }^{12}$ Starting point is the following continuous earnings function:

$$
W_{i j, t}=W_{i j, 0}+r_{c i} \int_{s=0}^{t} C_{i j, s} d s
$$

in which $W_{i j, t}$ is the wage paid to a worker with educational background $i$ employed in occupation $j$ with job tenure $t, C_{i j, t}$ are the training costs made after $t$ years of job tenure and $r_{c i}$ is the rate of return on training. Equation (2.7) differs in two ways from the earnings function used by Mincer. In the first place, the earnings are related to both the educational background and the occupation in which the worker is employed, while Mincer uses a human capital function in which only educational characteristics can be found. Secondly, Mincer uses the term 'earnings capacity' instead of earnings. Because in this paper it is assumed that the firm bears the training costs, the distinction between earnings capacity and earnings is not relevant here. ${ }^{13}$

Mincer assumes that the rate of return is a decreasing function of age. In this paper, the rate of return $r_{c i}$ is assumed to be related to the quality $q_{c}$ of the training and the learning ability $L A I_{i}$ of the worker with educational background $i$ :

$$
r_{c i}=q_{c} L A I_{i}
$$

Both determinants are positively related to the rate of return on training. The higher the learning ability, the more effective the training will be. The quality (or effectiveness) measure $q_{c}$ can be interpreted in two ways. In the first place as a direct measure of the quality of the training course and, secondly as a measure of the degree of alignment between the skills acquired in the training concerned and required skills. In both cases the rate of return is an increasing function of the quality. ${ }^{14}$

Finally, an assumption has to be made with regard to the allocation of training efforts over time. In this paper, it is assumed that the training cost function looks as follows: ${ }^{15}$

$$
C_{i j, t}=C_{i j, 0} e^{-L A l_{i} t}
$$

12. See Mincer (1974), chapter 5.

13. See section 5 for more details.

14. Note that the rate of return is related to the educational background only. The occupation in which the worker is employed plays no role. In other words, the assumption is made that the effectiveness of training is not related to the context in which training takes place.

15. This specification is one of four alternatives presented by Mincer (1974). 
Equation (2.9) implies that the training cost function is convex. Furthermore, the higher the learning ability, the faster the training efforts decrease with job tenure. That is, the higher the learning ability, the more convex the training cost function is.

Substituting (2.8) and (2.9) into (2.7) and solving yields the following earnings function:

$$
W_{i j, t}=W_{i j, 0}+q_{c} C_{i j, 0}-q_{c} C_{i j, 0} e^{-L A l_{i} t}
$$

Equation (2.10) has the same functional form as equation (2.4):

$$
W_{i j, t}=W_{j}^{p}-M M_{i j} e^{-L A l_{i} t}
$$

Comparing (2.4) and equation (2.10) yields the following identities:

$$
q_{c} C_{i j, 0}=M M_{i j}
$$

and:

$$
W_{i j, 0}+q_{c} C_{i j, 0}=W_{j}^{p}
$$

Equation (2.11) shows that, given the quality of the training concerned $q_{c}$, the degree of mismatch $M M_{i j}$ determines the initial training effort and costs $C_{i j, 0}$. Equation (2.12) shows the link between the initial wage $W_{i j, 0}$ and the long run wage $W_{j}^{P}$. Substituting (2.11) into (2.12) yields equation (2.5):

$$
W_{i j, 0}=W_{j}^{p}-M M_{i j}
$$

which shows that the difference between the initial wage and the long run wage is equal to the quality of the match measure.

The total training costs, which have to be made in order to bring a worker on the long run productivity level, can be derived from the training cost function (2.9):

$$
T C_{i j}=\int_{t=0}^{4} C_{i j, 0} e^{-L A l_{i} t}=\frac{C_{i j, 0}}{L A l_{i}}
$$

Substituting (2.8) into (2.13) yields:

$$
T C_{i j}=\frac{q_{c} C_{i j, 0}}{r_{c i}}=\frac{M M_{i j}}{r_{c i}}=\frac{M M_{i j}}{q_{c} L A l_{i}}
$$


Equation (2.14) shows that the total training costs are an increasing function of the degree of mismatch and a decreasing function of the training quality and the learning ability.

In this section a model is formulated to investigate the relation between the quality of the match, earnings and training. Section 3 pays more attention to the relation between the quality of the match and initial earnings.

\section{Measuring the quality of the match}

\subsection{Introduction}

An important feature of the earnings model, which has been formulated in section 2 , is the assumption that the initial wage is an increasing function of the quality of the match between the worker's educational background and the occupation in which he is employed. The difference between the long run wage and the initial wage can be considered to be a monetary measure of the quality of the match. However, section 2 did not clarify the relation between this monetary measure and the degree of alignment between the skills acquired in the type of education and the skill required in the occupation concerned. This section formulates a method to investigate this relation.

The quality of the match has two dimensions: the skill level and the subject of the skills. Therefore, this section consists of two parts. First, the relation between the initial wage within an occupation and the educational level is discussed. In the second place, attention is paid to the degree of alignment between the educational subject and the occupational field. This element is added to the model describing the relation between the initial wage and the educational level.

\subsection{The educational level and the initial wage}

In the job matching literature attention has been paid to the consequence of a mismatch between required and acquired skills on the rate of return on education. These studies focus on the effect of the educational level. Table 3.1 shows the estimation results of five studies: Hartog and Oosterbeek (1988), Sicherman (1991), Van Smoorenburg and Van der Velden (1995), Cohn and Khan (1995) and Sloane et al. (1995). ${ }^{16}$

16. In footnote 2 a recent study by Oosterbeek and Webbink has been mentioned. This study is not used here, because it discusses no aggregate results, but rate of return estimates by gender only. 
Table 3.1

Studies on the rate of return on education

\begin{tabular}{lccccc}
\hline & $\mathrm{H} \& \mathrm{O}$ & $\mathrm{S}$ & $\mathrm{S} \& \mathrm{~V}$ & $\mathrm{C} \& \mathrm{~K}$ & $\mathrm{~S}, \mathrm{~B} \& \mathrm{~S}$ \\
\hline education required & 0.071 & 0.048 & ref & 0.077 & 0.178 \\
undereducation & -0.025 & -0.017 & -0.022 & -0.038 & -0.034 \\
overeducation & 0.057 & 0.039 & -0.027 & 0.049 & 0.028 \\
\hline
\end{tabular}

The figures presented in table 3.1 should be interpreted as follows. ${ }^{17}$ Take, for example, Hartog's and Oosterbeek's ( $\mathrm{H} \& \mathrm{O})$ estimates. The rate of return on years of education required is $7.1 \%$. Years overeducated yield a positive return also. However, the rate of return on overeducation is lower than on years required $(5.7 \%$ instead of $7.1 \%)$. Furthermore, being undereducated implies that the rate of return on additional schooling is $2.5 \%$ lower compared with the rate of return on being adequately educated. In other words, the rate of return is $4.6 \%$. Table 3.1 shows that Sicherman (S), Van Smoorenburg and Van der Velden (S\&V), ${ }^{18}$ Cohn and Khan $(\mathrm{C} \& \mathrm{~K})$ and Sloane et al. $(\mathrm{S}, \mathrm{B} \& \mathrm{~S})^{19}$ find comparable results. The rate of return on years required is higher than the rate of return on both underand overeducation. Furthermore, the more recent studies show that the rate of return on years undereducated may be higher than on years overeducated (Van Smoorenburg and Van der Velden and Sloane et al.). Cohn and Khan conclude the opposite, however. They find that the rate of return on years overeducated is $4.9 \%$, while being undereducated implies that the rate of return is $3.9 \%$.

From table 3.1 it can be concluded that the rate of return $R$ on both years overeducated $(O E>0)$ and years undereducated $(O E<0)$ is lower than on years required $(O E=0){ }^{20}$ Furthermore, the rate of return on years overeducated may be lower than on years undereducated, although the estimates are not unambiguous. Figure 3.1 summarizes these conclusions. These rate of return estimates imply that, in a particular job, the

17. For more details, see Hartog and Oosterbeek (1988).

18. Note that Hartog and Oosterbeek (1988), Sicherman (1991), Cohn and Khan (1995) and Sloane et al. (1995) have estimated the rate of return on required years, years overeducated and years undereducated, while Van Smoorenburg and Van der Velden (1995) have considered the required years as the reference and have estimated the difference between the rate of return on years required on the one hand and the years under- or overeducated on the other hand.

19. With regard to the rate of return on education required, Sloane et al. make a distinction between five educational levels. The figure shown here is the rate of return on the third level. The rates of return vary form $8.5 \%$ on the lowest level to $46.8 \%$ on the highest level.

20. Note that in this paper two types of rate of return are distinguished. In the first place, the rate of return on education $R$ and the rate of return on training $r_{c}$. 
undereducated earn much less, while the overeducated earn only slightly more than those whose educational level is in alignment with the requirements.

An important weakness of these studies is the fact that the optimal educational level, under- and overeducation are defined by means of subjective or indirect methods, which focus on determining the 'optimal' level. Therefore, these rate of return studies are restricted. First, the quality of the match can not be determined objectively. Second, these studies only focus on the difference between the rate of return on adequate schooling on the one hand, and under- or overeducation on the other. The methods which are used in these studies to determine the optimal educational level imply that they are not able to measure the degree of over- and undereducation. Therefore, the rate of return on education can not be related to the degree of under- or overeducation. Figure 3.1 reflects this drawback. Irrespective of the degree of under- or overeducation, the rate of return is constant.

Figure 3.1

Estimates of the rate of return on education: conclusion

The aim of this section is find a method to use the monetary mismatch measure $M M_{i j}$ to determine the quality of the match between acquired and required skills. In other words, the aim is to find a measure for the degree of under- or overeducation. Before describing the method, two remarks have to be made. First, attention has to be paid to the terms 'perfect match' and 'comparative advantage'. A distinction has to be made between the type of 
education which matches perfectly with a particular occupation and a type of education which has a comparative advantage in the occupation concerned. The perfect match is a partial concept; it simply indicates that the acquired and required skills are perfectly in alignment. Comparative advantage, however, indicates the degree of alignment compared with other types of education. The concepts under- and overeducation are used in a comparative advantage context here. This means, for example, that overeducation implies that the educational level is higher than the educational level which has a comparative advantage in the occupation concerned. Second, the concept of 'rate of return on education' has to be defined properly. Take two types of education $i$ and $i^{*}$. Type of education $i$ has a higher level than $i^{*}$. In the context of this paper, the rate of return $R_{i j}$ on type of education $i$ for an individual employed in occupation $j$, already having type of education $i^{*}$, is equal to:

$$
R_{i j}=\frac{W_{i j, 0}-W_{i^{*} j, 0}-E C_{i}}{E C_{i}}
$$

The rate of return is equal to the ratio of, on the one hand, the difference between the wage gain $W_{i j, 0}-W_{i^{*} j, 0}$ and the educational costs $E C_{i}$ and, on the other hand, the educational costs $E C_{i}$.

The method to measure the quality of the match is based on the conclusions drawn from the rate of return studies mentioned above. These conclusions have been shown in figure 3.1. Furthermore, an additional assumptions is made. The rate of return is assumed to be related to the degree of under- and overeducation. This assumption is shown in figure 3.2.

Figure 3.2

Rate of return and the degree of under- and overeducation 
The dotted lines in figure 3.2 are the same as the lines shown in figure 3.1. The continuous lines reflect the assumptions made here. In the first place, if the individual is employed in occupation $j$, the highest rate of return $R_{j}^{c a}$ is achieved on the educational level which has a comparative advantage. Secondly, the rate of return is a decreasing function of the degree of under- or overeducation. Finally, the line describing the link between overeducation and the rate of return is steeper; the negative effect on the rate of return on overeducation is greater than the effect on undereducation.

Figure 3.2 can be described by means of the following equation:

$$
\begin{array}{cl}
R_{i j}=\mathrm{Y}_{0}-\mathrm{V}_{1}\left(L V_{j}^{c a}-L V_{i}\right) & \text { for } L V_{i}<L V_{j}^{c a} \\
R_{i j}=\mathrm{Y}_{0} & \text { for } L V_{i}=L V_{j}^{c a} \\
R_{i j}=\mathrm{Y}_{0}-\mathrm{Y}_{2}\left(L V_{i}-L V_{j}^{c a}\right) & \text { for } L V_{i}>L V_{j}^{c a}
\end{array}
$$

in which $L V_{i}$ is the level of type of education $i$ and $L V_{j}^{c a}$ is the educational level which has a comparative advantage in occupation $j .{ }^{21}$ Equation (3.2) contains three parameters. The assumptions described by figure $3.1 \mathrm{imply}$ that these parameters are assumed to have the following characteristics. In the first place, $\mathrm{v}_{0}=R_{j}^{c a}$; if an individual has the educational level which has a comparative advantage in the occupation concerned, the rate of return on his educational efforts are maximal. Second, $V_{1}, Y_{2}>0$; both under- and overeducation have a negative effect on the rate of return. Third, $V_{2}>V_{1}$; the negative effect of overeducation on the rate of return is greater than the negative effect of undereducation.

In order to translate the degree of under- or overeducation into the monetary mismatch measure $M M_{i j}$, the impact of under- and overeducation on the wage has to be measured. Equation (3.1) describing the link between initial wages and the rate of return can be used here. If the assumption is made that the educational costs are constant and not related to the educational level, then:

$$
R_{i j}=\frac{\mathrm{M} W_{i j, 0}}{\mathrm{M} L V_{i}}
$$

This implies by definition:

21. Note that the assumption is made that there is one unique level which has a comparative advantage. 
$W_{i j, o}=\int R_{i j}\left(L V_{i}\right) d L V_{i}$

Substituting (3.4) into equation (3.2) and solving yields:

$$
\begin{array}{cc}
W_{i j, 0}=\gamma_{0} L V_{i}-\gamma_{1} L V_{j}^{c a} L V_{i}+\frac{1}{2} \gamma_{1} L V_{i}^{2}+C_{1} & \text { for } L V_{i}<L V_{j}^{c a} \\
W_{i j, 0}=\gamma_{0} L V_{i}+C_{2} & \text { for } L V_{i}=L V_{j}^{c a} \\
W_{i j, 0}=\gamma_{0} L V_{i}+\gamma_{2} L V_{j}^{c a} L V_{i}-\frac{1}{2} \gamma_{2} L V_{i}^{2}+C_{3} & \text { for } L V_{i}>L V_{j}^{c a}
\end{array}
$$

In order to obtain a continuous wage function, the following assumptions have to be made:

$$
C_{2}=C_{1}-\frac{1}{2} \mathrm{~V}_{1}\left(L V_{j}^{c a}\right)^{2}
$$

and:

$$
C_{2}=C_{3}+\frac{1}{2} \mathrm{Y}_{2}\left(L V_{j}^{c a}\right)^{2}
$$

Substituting (3.6a) and (3.6b) into (3.5) and rewriting yields equation (3.7), which describes how the initial wage is related to the degree of over- or undereducation:

$$
\begin{aligned}
& W_{j, 0}^{c a}-W_{i j, 0}=V_{0}\left(L V_{j}^{c a}-L V_{i}\right)-\frac{1}{2} \gamma_{1}\left(L V_{j}^{c a}-L V_{i}\right)^{2} \text { for } L V_{i} \# L V_{j}^{c a} \\
& W_{i j, 0}-W_{j, 0}^{c a}=V_{0}\left(L V_{i}-L V_{j}^{c a}\right)-\frac{1}{2} \mathrm{~V}_{2}\left(L V_{i}-L V_{j}^{c a}\right)^{2} \text { for } L V_{i}>L V_{j}^{c a}
\end{aligned}
$$

Now the link with the mismatch measure $M M_{i j}$ can be made. As stated before, a distinction has to be made between the type of education which matches perfectly and the type of education which has a comparative advantage. In other words, if a type of education has a comparative advantage in a particular occupation, the acquired skills may not match perfectly with the required skills. Now define:

$$
M M_{j}^{c a}=W_{j}^{p}-W_{j}^{c a}
$$


Furthermore, as stated before:

$W_{i j, 0}=W_{j}^{p}-M M_{i j}$

Substituting (2.5) and (3.8) into the wage equation (3.7) yields the relation between the monetary mismatch measure and the degree of over- or undereducation:

$$
\begin{aligned}
& M M_{i j}=M M_{j}^{c a}+\mathrm{V}_{0}\left(L V_{j}^{c a}-L V_{i}\right)-\frac{1}{2} \gamma_{1}\left(L V_{j}^{c a}-L V_{i}\right)^{2} \text { for } L V_{i} \# L V_{j}^{c a} \\
& M M_{i j}=M M_{j}^{c a}-\gamma_{0}\left(L V_{i}-L V_{j}^{c a}\right)+\frac{1}{2} \gamma_{2}\left(L V_{i}-L V_{j}^{c a}\right)^{2} \text { for } L V_{i}>L V_{j}^{c a}
\end{aligned}
$$

In figure 3.3 the mismatch equation (3.7') is drawn. Figure 3.3 shows that the curve is Sshaped. The monetary mismatch measure is not a linear function of the degree of alignment between the required and the acquired skills. Furthermore, the function is not symmetric; the negative effect of undereducation on the initial wage is assumed to be greater than the positive effect of overeducation. ${ }^{22}$ The mismatch function has a point of inflection at $L V_{i}-L V_{j}^{c a}=0$. If an individual is undereducated, more education yields a higher rate of return, while for overeducated more education implies a lower rate of return. At the point of inflection, the rate of return is maximal; more education has a maximal impact on the quality of the match and, therefore, on the wage.

Up till now, the impact of a mismatch between the level of a type of education and the level of the required skills in an occupation on the wage is discussed. Skills have a second dimension, however, the subject. In the remainder of this section the focus is on adding the subject to the model described above.

Figure 3.3

Measuring the degree of over- and undereducation by means of initial wages

22. This asymmetry is related to the assumption that $Y_{2}>Y_{1}$. 


\subsection{The subject of study and the initial wage}

Adding the subject of the skills to the model causes several problems. First, in contradiction to the level, the concept 'subject' is not ordinal. This implies that measuring the degree of alignment between the subject of, on the one hand, the acquired skills and, on the other hand, the required skills is difficult. In the second place, the question arises wether the impact of a mismatch with regard to the subject is related to the degree of mismatch with regard to the level. This relation may be complex. For example, is a gap between the subject of the acquired and the required skills a more serious problem for the higher skilled, or not? Third, studies dealing with the impact of mismatch with regard to the subject are rare.

Therefore, in this paper a simple approach is chosen. The underlying idea is comparable with the thoughts on which subsection 3.2 is based. It is assumed that, given the tasks contents of the occupation concerned, there is one subject of study which has a comparative advantage in the occupation. The rate of return on the types of education within this subject is higher than the rate of return on other types of education of other workers in that occupation. Because the concept subject is ordinal, the degree of alignment between the subject which has a comparative advantage and the subject of other types of education is assumed to play no role. Furthermore, the assumption is made that the size of the negative effect of a mismatch with regard to the subject on the rate of return is not related to the level of the skills.

Equation (3.7') can be considered to describe a model dealing with types of education which subject is alignment with the occupation concerned. If $S_{j}^{c a}$ is defined as the subject of study which has a comparative advantage in occupation $j$, equation (3.9) describes the consequences of a mismatch with regard to the subject for the rate of return:

$$
\begin{gathered}
R_{i j}^{S=S^{c a}}=R_{i j} \text { for } S_{i}=S_{j}^{c a} \\
R_{i j}^{\text {SÖS }}=Y_{3} R_{i j} \text { for } S_{i} \text { Ö } S_{j}^{c a}
\end{gathered}
$$


in which $R_{i j}$ is the rate of return on the level of the skills. A mismatch is assumed to have a negative effect on the rate of return, which implies that $0<v_{3}<1 .^{23}$

The specification of the effect of a mismatch with regard to the subject used here has the following consequences. In the first place, no distinction has to be made here between the concepts of 'a perfect match' and 'a comparative advantage'. If a type of education has a comparative advantage in the occupation concerned, the subject of study is perfectly in alignment with the required skills. Second, the higher the educational level, the more serious the mismatch between required and acquired skills is. Assume that a type of education has a comparative advantage with regard to the level while the subject of study is not alignment with the requirements in occupation $j$. Then: ${ }^{24}$

$$
W_{j, 0}^{c a}-W_{i j, 0}=Y_{3} L V_{i}^{c a}
$$

More general, the initial wage difference between a type of education which subject matches and a type of education which subject does not match, while both types of education are of the same level is equal to $\gamma_{3} L V_{1}$. This implies that equation (3.7') can be extended to incorporate the subject of study:

$$
\begin{array}{ll}
=M M_{j}^{c a}+\gamma_{0}\left(L V_{j}^{c a}-L V_{i}\right)-\frac{1}{2} \gamma_{1}\left(L V_{j}^{c a}-L V_{i}\right)^{2} \quad \text { for } L V_{i} \# L V_{j}^{c c} \\
V_{j}^{c a}+\gamma_{0}\left(L V_{j}^{c a}-L V_{i}\right)-\frac{1}{2} \gamma_{1}\left(L V_{j}^{c a}-L V_{i}\right)^{2}+\gamma_{3} L V_{i} & \text { for } L V_{i} \# L V_{j}^{c a} \\
=M M_{j}^{c a}-\gamma_{0}\left(L V_{i}-L V_{j}^{c a}\right)+\frac{1}{2} \gamma_{2}\left(L V_{i}-L V_{j}^{c a}\right)^{2} \quad \text { for } L V_{i}>L V_{j}^{c a} \\
M_{j}^{c a}-\gamma_{0}\left(L V_{i}-L V_{j}^{c a}\right)+\frac{1}{2} \gamma_{2}\left(L V_{i}-L V_{j}^{c a}\right)^{2}+\gamma_{3} L V_{i} \text { for } L V_{i}>L V_{j}^{c c}
\end{array}
$$

In figure 3.4 the extended mismatch equation (3.11) is shown. Figure 3.4 shows that if the subject of study is not in alignment with the requirements $\left(S_{i} O S_{j}^{c a}\right)$, the monetary mismatch measure is higher than if there is a perfect match between the subject of the acquired and the required skills $\left(S_{i}=S_{j}^{c a}\right)$. Figure 3.4 shows also that the higher the educational level, the more serious a subject mismatch is. The higher the educational level, the more skills are acquired and the more serious a mismatch is (in absolute terms).

23. Implicitly it is assumed here that $R_{i j}>0$.

24. Note that $W_{j, 0}^{a c}$ is the wage paid to workers having an educational background which has a comparative advantage with regard to both the level and the subject of study. 
In section 2 a model is formulated which describes the relation between the quality of the match, training and earnings. The model in section 3 pays more attention to the monetary mismatch measure which has been derived in section 2 and the degree of alignment between required and acquired skills. The models formulated in section 2 and 3 are tested in the remainder of this paper. In section 4 the models will be transformed into testable models.

Figure 3.4

The extended mismatch equation

\section{Towards an empirical model}

\subsection{Introduction}

Up till now, the theoretical framework of this paper has been described. This framework consists of two parts. In the first place, the relation between the quality of the match, training and earnings. In the second place, the method to determine the quality of the match between acquired and required skills by means of initial wages. This section deals with the instruments which are used to investigate the validity of the framework empirically. This section consists of three parts. First, some variables to which earnings are related are added to the model. Second, a linear approximation of the earnings function (2.4), which 
plays a central role in this paper, is derived. Furthermore, some hypotheses with regard to the signs and magnitudes of the parameters are formulated. Finally, the method which is used to investigate the relation between the quality of the match and training is discussed.

\subsection{Determinants of the wage}

In section 2 a model is formulated which describes the relation between the wage on the one hand and the educational background of the worker and the occupation in which he is employed, on the other hand. It was shown, that in the short run, both the educational background and the occupation concerned are important. In the long run, however, the educational background plays no role anymore with regard to the productivity in an occupation. Differences in productivity between workers having various types of education have then disappeared by means of additional training. The earnings function (2.4) reflects this distinction between the short and the long run:

$$
W_{i j, t}=W_{j}^{p}-M M_{i j} e^{-L A l_{i} t} \quad M M_{i j}, L A I_{i} \$ 0
$$

in which $W_{j}^{p}$ is the long run wage which is paid to a worker whose skills match perfectly with the skill required in occupation $j$. If the firm is price-taking and profit-maximising $W_{j}^{p}$ also reflects the (marginal) productivity of the 'perfectly matching worker'. In practice, however, the productivity and earnings in a job are not only determined by the degree of alignment between the acquired and required skills. Beside the educational background and the occupation, there are other worker and job characteristics which are related to the productivity and earnings. Therefore, in this paper, the earnings are assumed to be related to some worker and job characteristics apart from the occupation. Therefore, equation (2.4) is reformulated as follows:

$$
W_{h i j, t}=W_{j}^{p}+X_{h j} \beta-M M_{i j} e^{-L A l_{i} t} \quad M M_{i j}, L A I_{i} \$ 0
$$

in which $W_{h i j, t}$ is the wage earned by individual $h$ with educational background $i$ employed in occupation $j$. The vector $x_{h j}$ reflects the worker and job characteristics which are used as explaining variables of the wage. Gender and the marital status are the worker characteristics which are added to the model. The job characteristics which are added are: the industry in which the worker is employed, the distinction between the private and the public sector, the firm size, hours worked (that is, full-time or part-time) and the distinction between permanent and temporary work. 
Arguments to include particular variables in the earnings function can especially be found in the human capital literature. ${ }^{25}$ The link between earnings, training and the turnover rate plays an essential role. In this paper the emphasis is on the link between mismatch and training. There are other determinants of the training efforts, however. The higher the (expected) rate of return on training, the greater the training efforts and the higher earnings will be. The rate of return on training is, for example, linked with ability and the turnover rate.

Gender and the marital status are the worker characteristics which are added to the model. Mincer (1989) states that women receive less training than men. An explanation for this finding may be that employers expect women to have a higher turnover rate than men. As a result, for women earnings are expected to be lower than for men. The marital status has a similar effect. If a worker is married, the turnover rate is expected to be lower (Mincer, 1989).

The following arguments can be used to explain the inclusion of the job characteristics mentioned above. Large firms are able to offer more training facilities to their workers (Ehrenberg and Smith, 1994). Furthermore, the turnover rate may be lower in a larger firm. Therefore, in large firms earnings are expected to be higher. Empirical research shows, indeed, that training efforts are positively related to the size of the firm (Mincer, 1989). An analogue argument can be used to include the length of the contract into the model. Being temporarily employed implies a higher turnover rate and a lower expected rate of return on training. Therefore, it may be reasonable to assume that temporarily employed workers receive lower earnings. In the literature dealing with earnings functions, hours worked is often used as a explaining variable (see Psacharopoulos, 1987). Adding the hours worked to the model may be done for two contradictory reasons. On the one hand, part-time workers may have a higher hourly productivity level, because they may work more intensively. On the other hand the rate of return on training may be lower because a part-time worker by definition never will have as much time as a full-time employed worker to profit from his training efforts. In other words, earnings for part-time workers may be both higher or lower than the wage for full-time workers. Finally, two industry variables are added. These variables are often used in the earnings function literature (see Psacharopoulos, 1987). In the first place, a distinction is made between the private and the public sector. Second, several industries are distinguished. These variables are included to take differences between industries with regard to earnings into account.

\subsection{An empirical model of the earnings function}

25. For an overview of research on earnings functions and arguments to include particular explanatory variables in the model, see, for example, Psacharopoulos (1987) or Ehrenberg and Smith (1994). 


\section{A linear approximation}

The earnings equation (4.1) shows the relation between the wage on the one hand and job tenure on the other. Unfortunately, this equation is not linear in the parameters. In this paper, a linear approximation by means of a Taylor's series is used. If the earnings function (4.1) is expanded in a second-order Taylor's series about $t=0$, the following equation can be obtained: ${ }^{26}$

$$
\begin{aligned}
& W_{h i j, t}=W_{j}^{p}+X_{h j} \beta-M M_{i j}+L A l_{i} M M_{i j} t-\frac{1}{2} L A l_{i}^{2} M M_{i j} t^{2} \\
& \text { The hypotheses }
\end{aligned}
$$

By estimating equation (4.3): $:^{27}$

$$
W_{h i, t}=\alpha_{j}+X_{h j} \beta+\theta_{1, i j}+\theta_{2, j i} t+\theta_{3, j} t^{2}+u_{h i j}
$$

the theoretical framework described above can be analysed empirically. Equation (4.3) contains three parameter sets. In the first place $\alpha_{j}$, which is a measure for the long run wage $W_{j}^{p}$. In the second place, the parameters $\theta_{1}, \theta_{2}$ and $\theta_{3}$. These parameters determine the relation between job tenure on the one hand and the actual wage on the other hand. In the third place, the parameters which make up the vector $\beta$. These parameters measure the relation between the worker and job characteristics on the one hand and the wage on the other hand.

The parameter $\alpha_{j}$ is expected to be an increasing function of the occupational level. The higher the occupational level, that is: the higher the skill requirements, the higher the (long run) productivity will be. With regard to the parameters $\theta_{1}, \theta_{2}$ and $\theta_{3}$, the following two hypotheses are formulated. In this paper the emphasis is on $\theta_{1}$, which is an estimator of the mismatch measure $M M_{i j}$. Section 3 yields the hypotheses with regard to $M M_{i j}$. First, $\theta_{1}$ may expected to be negative; a mismatch between required and acquired skills has a negative effect on the wage. Second, an S-shaped relation between $M M_{i j}$ and the educational level has been derived, which has been shown in figure 3.3. Furthermore, in figure 3.4 it has been shown that, given the educational level, $M M_{i j}$ is higher if the subject of study is not in alignment with the requirements. So, it may be expected that, within an occupation, the relation between $\theta_{1}$ and the educational level is S-shaped. Furthermore, if the subject of a type of education is not in alignment with the occupation concerned, (the absolute value of) $\theta_{1}$ will be higher.

26. An expansion about $t=0$ is used, because the emphasis in this paper is on the mismatch between occupations and types of education and, consequently, the earnings of workers without experience in the job concerned. The derivation of this equation can be found in appendix 1 .

27. Note that using a second-order Taylor-series implies that the remaining elements of the infinite Taylor-series are included in the error term $u_{h i j}$. 
The second parameter, $\theta_{2}$ is expected to be positive; due to on-the job training and jobrelated training, job tenure $t$ is expected to have a positive effect on the wage. Furthermore, equation (4.4) shows that $\theta_{2} /-\theta_{1}$ can be considered to be an estimator for the learning ability index $L A I_{i}$ :

$$
L A I_{i}=\frac{L A I_{i} M M_{i j}}{M M_{i j}}=\frac{\theta_{2}}{-\theta_{1}}
$$

In section 2 it has been stated that it may be expected that $L A I_{i}$ is positively related to the educational level. Finally, $\theta_{3}$ is expected to be negative; that is the earnings function is expected to be concave.

With regard to the parameters of the vector $\beta$, subsection 4.2 yields the hypotheses. Being male and being married may have a positive effect on earnings. Furthermore, being employed in a large firm also may have a positive effect. In a large firm, the wage is expected to be higher. Being permanently employed is also expected to have a positive effect on the wage. The effect of being employed part-time may be both positive or negative. Finally, determining the effect of the industry in which the worker is employed is difficult and is likely to be related to the occupation concerned.

\subsection{An empirical model of the training cost function}

In section 2 it has been assumed that the training costs $C_{i j, t}$ are a decreasing function of job tenure:

$$
C_{i j, t}=C_{i j, 0} e^{-L A l_{i} t}
$$

As stated before, according to the human capital theory, there is a close link between training efforts and earnings. Therefore, the control variables added to the earnings function are also used here. To simplify the analysis an additive model is used:

$$
C_{h i j, t}=\mu_{j}+X_{h j} \eta+C_{i j, 0} e^{-L A l_{i} t}
$$

Analogous to the earnings function, a second-order Taylor-series can be used to approximate the training cost function (4.5) in order to make it linear in the parameters: ${ }^{28}$

$$
C_{h i j, t}=\mu_{j}+X_{h j} \eta+C_{i j, 0}-L A I_{i} C_{i j, 0} t+\frac{1}{2} L A I_{i}^{2} C_{i j, 0} t^{2}
$$

28. A derivation of this equation can be found in appendix 1 . 
Equation (4.6) contains the unknown variable $C_{i j, 0}$. Remind, however, that in section equation (2.11) has been derived:

$$
q_{c} C_{i j, 0}=M M_{i j}
$$

Re-arranging (2.11) and substituting into (4.6) yields:

$$
C_{h i j, t}=\mu_{j}+X_{h j} \eta+\frac{M M_{i j}}{q_{c}}-\frac{L A I_{i} M M_{i j}}{q_{c}} t+\frac{1}{2} \frac{L A I_{i}^{2} M M_{i j}}{q_{c}} t^{2}
$$

So, by estimating equation (4.8):

$$
C_{h i j, t}=\mu_{j}+X_{h j} \eta+\phi_{1, i j} M M_{i j}+\phi_{2, i j} M M_{i j} t+\phi_{3, i j} M M_{i j} t^{2}+u_{h i j}
$$

the theoretical training cost function can be tested empirically.

With regard to the parameters in equation (4.8), the following hypotheses can be formulated. In the first place, $\phi_{1}$ is expected to be positive; the training costs are expected to be positively related to the degree of mismatch between the occupation and the type of education concerned. In the second place, the training costs are assumed to be a decreasing, convex function of job tenure. This implies that $\phi_{2}$ is assumed to be negative and $\phi_{3}$ is expected to be positive. The parameters which make up the vector $\eta$ are expected to have the same signs as the parameters of the vector $\beta$. Males and married workers are expected to receive more training. Furthermore, workers employed in a large firm, workers who have a permanent contract and workers who are full-time employed are expected to receive more training. Finally, the industry variables are added to take industrial differences with regard to the training efforts into account.

\section{The data}

\subsection{The data set}

The OSA labour supply survey is used here for the empirical analysis. This survey includes data with regard to the Dutch labour market in general and the labour market behaviour of the (potential) labour force in particular. The survey deals with individuals who are between 16 and 65 years old and do not attend full-time education. It is a panel data set of which the respondents are surveyed biennially. For this paper the survey of 1992 is used. The number of respondents was $4,536 .{ }^{29}$ For this paper a selection of respondents is used. This selection includes those who have a paid job, are not self-employed and are graduated.

29. More information can be found in Allaart et al. (1993). 
Excluding the respondents whose labour market position (especially the occupation in which they are employed and the educational background) are not known, implies that finally 2,039 individuals remain in the data set used here.

A few remarks have to be made with regard to the variables used. In the first place, the wage variable used here is the full-time equivalent of the net monthly wage. That is, it is the net monthly wage if a worker would be employed full-time (that is, working a forty-hour week). ${ }^{30}$ Job tenure is defined as the number of years experience in the occupation concerned. The other variables used in the wage equation are dummies. A worker is considered to be part-time employed if he works less than 33 hours a week. A firm is considered to be large if more than 50 people are employed. The dummies for gender, martial status, a permanent contract and the distinction between public and private sector require no further explanation.

With regard to three variables, the classification is important. In the first place, 7 economic industries are distinguished. This classification is based on the Standard Industry Classification 1978 of Statistics Netherlands, which is related to the International Standard Industry Classification (ISIC), on the one-digit level. The occupational classification is based on the Standard Occupation Classification 1984 of Statistics Netherlands. On the one-digit level, this classification distinguishes ten main occupational groups. Furthermore, 7 occupational levels are distinguished. These levels are based on a classification of the Dutch Ministry of Social Affairs and Employment. The educational classification is based on the Standard Educational Classification 1978 (SOI 1978) of Statistics Netherlands, which is related to the International Standard Classification of Education (ISCED). In this classification 6 educational levels are distinguished. With regard to the subject a classification developed by ROA is used (see, for example, Research Centre for Education and the Labour Market, 1993). In this classification 4 subjects are distinguished. More details with regard to these classifications can be found in appendix 2 .

Finally, attention has to be paid to the training variable. In the theoretical framework, the training costs play an important role. The aim was to approximate these costs by means of a training efforts measure: the time spent on training. Unfortunately, the data on this variable are unsatisfying; the number of respondents who gave information on the training efforts was rather low. Therefore, the choice has been made to use a dummy variable as dependent variable in the training equation. A distinction is made between those workers

30. From a theoretical point of view, using gross wage figures would be more preferable. Unfortunately, these figures were not available. Two control variables which are used enable to take differences with regard to the tax burden into account: the martial status and the number of hours worked. 
who receive training and those who don't. Furthermore, in order to have a proxy for jobrelated training, only training which is paid by the firm is taken into account. ${ }^{31}$

\subsection{Some descriptive statistics}

One of the starting-points for this paper was the notion that a mismatch with regard to the required skills (the occupation) and the acquired skills (the educational background) is a well-known phenomenon on the labour market. Table 5.1 illustrates this phenomenon by investigating the level of the skills. ${ }^{32}$

Assume that skills on respectively a low, intermediate and high level match with jobs on a low, intermediate and high level. Then table 5.1 shows that both under- and overeducation are important phenomena on the labour market. For example $35.6 \%$ of the workers having primary education (educational level 2) work on an intermediate level or higher (occupational level 3 or higher), while $10.5 \%$ of the academic graduates (educational level 6) are employed on an intermediate level (occupational levels 3 and 4).

Table 5.1

The occupational level by the educational level of workers in 1992 (in percents)

\begin{tabular}{|c|c|c|c|c|c|c|c|c|}
\hline \multirow[b]{2}{*}{ educ. level } & \multirow[b]{2}{*}{1} & \multirow[b]{2}{*}{2} & \multicolumn{3}{|c|}{ occupational level } & \multirow[b]{2}{*}{6} & \multirow[b]{2}{*}{7} & \multirow[b]{2}{*}{ total } \\
\hline & & & 3 & 4 & 5 & & & \\
\hline primary education & 18.6 & 43.8 & 22.4 & 7.6 & 3.8 & 1.8 & - & 100.0 \\
\hline LGSE \& PVE & 11.9 & 23.8 & 26.6 & 19.2 & 10.5 & 7.2 & 1.0 & 100.0 \\
\hline HGSE \& IVE & 4.2 & 14.0 & 24.9 & 24.2 & 17.3 & 12.8 & 2.7 & 100.0 \\
\hline HVE & - & 4.7 & 8.8 & 6.8 & 16.9 & 47.3 & 15.5 & 100.0 \\
\hline academic education & - & - & 7.9 & 2.6 & 2.6 & 52.6 & 34.2 & 100.0 \\
\hline all levels & 7.9 & 19.2 & 22.6 & 17.6 & 12.9 & 15.4 & 4.2 & 100.0 \\
\hline
\end{tabular}

Source: OSA

Table 5.2 illustrates the mismatch with regard to the subject. ${ }^{33}$

31. The argument for this restriction can be found in the human capital theory, which states that those who don't bear the risk have to make the training costs. This implies that the firm bears the costs of job-related training. This argument has first been made by Becker (1964).

32. The seven occupational and five educational levels which are distinguished in table 5.1 are also used in the empirical analysis in section 6 (see appendix 2).

33. The classification used here is based on the classification used in the empirical analysis in section 6 (see appendix 2). However, no distinction is made between general and commerce on the intermediate educational level here. 
Table 5.2

Occupational field by subject of study of workers in 1992 (in percents)

\begin{tabular}{|c|c|c|c|c|}
\hline \multirow[b]{2}{*}{ subject of study } & \multicolumn{3}{|c|}{ occupational field } & \multirow[b]{2}{*}{ total } \\
\hline & gen./comm. & tech./agr. & arts/care & \\
\hline general and commerce & 55.6 & 26.1 & 18.3 & 100.0 \\
\hline technical and agricultural & 16.1 & 74.6 & 9.2 & 100.0 \\
\hline arts and community care & 20.4 & 10.2 & 69.3 & 100.0 \\
\hline all subjects & 36.1 & 36.7 & 27.2 & 100.0 \\
\hline
\end{tabular}

Source: OSA

Table 5.2 shows that mismatch with regard to the subject is also an important phenomenon on the labour market. For example, $25.3 \%$ of the workers with an technical or agricultural background are employed in jobs which can not be characterised as technical or agricultural.

An important assumption on which the training model of section 2 was based was the training cost function (2.9):

$$
C_{i j, t}=C_{i j, 0} e^{-L A l_{i} t}
$$

Equation (2.9) reflects the assumption that job-related training is a decreasing function of job tenure. As stated before in this paper a binary variable is used as training variable. In table 5.3 the link between job tenure and the share of workers who receive training is described.

Table 5.3

Job tenure and the share of workers who receive training in 1992 (in percents)

\begin{tabular}{lccc}
\hline & $0-4$ & $\begin{array}{c}\text { job tenure (in years) } \\
5-8\end{array}$ & $>8$ \\
\hline share receiving training & 43.9 & 39.9 & 38.2 \\
\hline
\end{tabular}

Source: OSA

Table 5.3 shows that the share of workers receiving training indeed seems to be a decreasing function of job tenure.

Finally, in table 5.4 a list of descriptive statistics of the variables used in the analyses of this paper is given. 
Table 5.4

List of descriptive statistics (mean and standard deviation)

\begin{tabular}{|c|c|c|}
\hline variable & mean & SD \\
\hline monthly wage (in Dutch guilders) & 2676.44 & 1413.23 \\
\hline job tenure (in years) & 16.4 & 11.1 \\
\hline \multicolumn{3}{|l|}{ worker characteristics } \\
\hline male $(\%)$ & 63.3 & \\
\hline married $(\%)$ & 69.7 & \\
\hline \multicolumn{3}{|l|}{ educational background } \\
\hline primary (\%) & 10.3 & \\
\hline \multicolumn{3}{|c|}{ lower general secondary and preparatory vocational } \\
\hline general and commerce (\%) & 17.3 & \\
\hline technical and agricultural (\%) & 15.3 & \\
\hline community care (\%) & 5.8 & \\
\hline \multicolumn{3}{|c|}{ higher general secondary and intermediate vocational } \\
\hline general (\%) & 7.3 & \\
\hline technical and agricultural (\%) & 10.7 & \\
\hline commerce $(\%)$ & 9.7 & \\
\hline community care (\%) & 7.3 & \\
\hline \multicolumn{3}{|l|}{ higher vocational } \\
\hline commerce (\%) & 3.4 & \\
\hline technical and agricultural (\%) & 2.8 & \\
\hline arts and community services (\%) & 8.2 & \\
\hline \multicolumn{3}{|l|}{ academic } \\
\hline commerce (\%) & 0.3 & \\
\hline technical and agricultural (\%) & 0.3 & \\
\hline arts and community services (\%) & 1.2 & \\
\hline \multicolumn{3}{|l|}{ job characteristics } \\
\hline \multicolumn{3}{|l|}{ industry } \\
\hline agriculture and manufacturing (\%) & 19.2 & \\
\hline electricity, gas and water (\%) & 1.6 & \\
\hline construction (\%) & 7.2 & \\
\hline trade $(\%)$ & 16.6 & \\
\hline transport (\%) & 7.2 & \\
\hline private services (\%) & 10.4 & \\
\hline other services (\%) & 37.9 & \\
\hline large firm (\%) & 52.9 & \\
\hline private firm (\%) & 72.5 & \\
\hline part-time job (\%) & 26.6 & \\
\hline permanent job (\%) & 89.4 & \\
\hline
\end{tabular}

Source: OSA 


\section{Empirical analysis}

\subsection{Introduction}

In this section the empirical results are analysed. This section consists of four parts. In the first place, remind that the theoretical framework is based on the basic assumptions of the job matching. Therefore, the performance of the earnings model based on the assumption that both occupational and educational background characteristics determine earnings (job matching theory) is compared with the performance of the more restricted models. These more restricted models include, respectively, occupational (job competition model) and educational background characteristics only (human capital theory). Secondly, the estimates of the tenure-earnings profile by occupational level are presented. Thirdly, this profile is estimated by occupational field. Finally, the link between training efforts and the quality of the match is discussed. Investigating this link empirically enables to underpin the earnings model of section 2 .

\subsection{Testing three alternative earnings models}

The basic notion of this paper that the mismatch between the skills required in an occupation and the skills acquired in a type of education can be measured by means of investigating the initial wage of workers with the educational background concerned who are employed in that particular occupation. This basic idea relies heavily on the job matching theory. Therefore, following Hartog (1985), the starting-point for the empirical analysis is to investigate the performance of three alternative specifications of the earnings model. In the first place, the model which is used in this paper which is based on the job matching theory. In this model the educational background and the occupation determine the relation between earnings and job-tenure interactively: ${ }^{34,35}$

$$
W_{h i j, t}=\alpha_{j}+X_{h j} \beta+\theta_{1, i j}+\theta_{2, i j} t+\theta_{3, i j} t^{2}+u_{h i j}
$$

In the second place, a model based on the human capital theory; the educational background is the only determinant of the relation between earnings and job-tenure:

$$
W_{h i, t}=X_{h} \beta+\theta_{1, i}+\theta_{2, i} t+\theta_{3, i} t^{2}+u_{h i}
$$

34. This implies that comparative advantage plays an important role. Another option is a specification in which occupational and educational characteristics determine earnings independently. This specification is often referred to as the assignment model.

35. Note that equation (6.1a) is identical to equation (4.3). 
Finally, if the educational background plays no role, while the occupation in which the worker is employed determines the effect of job-tenure on earnings, the model is in accordance with the job competition model:

$$
W_{h j, t}=X_{h j} \beta+\theta_{1, j}+\theta_{2, j} t+\theta_{3, j} t^{2}+u_{h j}
$$

In the context of this analysis, the terms 'type of education' and 'occupation' refer to the level only. The subject is not taken into account. This choice is made to make the results comparable with previous research, which has for example been described by Hartog $(1985,1992)$ Table 6.1 describes the performance of respectively the job competition, the human capital and the job matching specification of the earnings model.

Table 6.1

The performance of three specifications of the earnings function

specification $R^{2}$

job competition model $\quad 0.23$

human capital theory 0.28

job matching theory 0.32

Table 6.1 shows that the job matching specification fits better than both the job competition and the human capital specification. Comparing the job competition and the job matching specification yields an F-statistic of 3.19, while comparing the human capital and the job matching specification yields an F-statistic of 1.72 . Both statistics are significant at the 1\%level. These findings are in alignment with previous research. It may be concluded that using the assumptions underlying the job matching theory in general and the principle of comparative advantage in particular is a reasonable starting-point for a further empirical analysis.

\subsection{The earnings function by occupational level}

The estimation results

In the OSA labour supply survey, 7 occupational levels are distinguished. In appendix 2 can be found that these seven levels can be aggregated to obtain three categories: unskilled and jobs on a low level (level 1 and 2), jobs on an intermediate level (level 3 and 4) and complex jobs (level 5,6 and 7). For each of these categories a separate earnings function (4.3) is estimated by means of Ordinary Least Squares. In table 6.2 the estimation results are presented. Note that the highest educational level acts as the reference level. 
Table 6.2

Tenure-earnings profiles by occupational level (net monthly wages in f.t.e in Dutch guilders)

\begin{tabular}{|c|c|c|c|c|c|c|}
\hline \multirow[b]{2}{*}{ variable } & \multicolumn{2}{|c|}{ low } & \multicolumn{2}{|c|}{$\begin{array}{l}\text { occupational level } \\
\text { intermediate }\end{array}$} & \multicolumn{2}{|c|}{ complex } \\
\hline & parameter & $\mathrm{t}$-value & parameter & $\mathrm{t}$-value & parameter & t-value \\
\hline$\overline{W_{j}^{p}}$ & 2062.72 & $9.23^{* *}$ & 2554.63 & $3.23^{* *}$ & 3705.59 & $10.03^{* *}$ \\
\hline $\begin{array}{l}M_{i j} \\
\text { primary education } \\
\text { LGSE \& PVE } \\
\text { HGSE \& IVE } \\
\text { HVE } \\
\text { academic education }\end{array}$ & $\begin{array}{c}-1164.97 \\
-1023.66 \\
-657.07 \\
\text { ref } \\
-\end{array}$ & $\begin{array}{l}-5.13^{* *} \\
-5.44^{* *} \\
-3.18^{* *}\end{array}$ & $\begin{array}{l}-1594.43 \\
-1065.43 \\
-907.02 \\
-720.67 \\
\text { ref }\end{array}$ & $\begin{array}{l}-2.72^{* *} \\
-2.38^{*} \\
-2.19^{*} \\
-1.81\end{array}$ & $\begin{array}{c}-2478.82 \\
-2097.58 \\
-2064.82 \\
-1898.73 \\
\text { ref }\end{array}$ & $\begin{array}{l}-1.81 \\
-4.49^{*} \\
-6.07 \\
-5.46\end{array}$ \\
\hline $\begin{array}{l}\text { job tenure } \\
\text { primary education } \\
\text { LGSE \& PVE } \\
\text { HGSE \& IVE } \\
\text { HVE } \\
\text { academic education }\end{array}$ & $\begin{array}{l}61.87 \\
63.98 \\
23.17 \\
\text { ref } \\
\quad-\end{array}$ & $\begin{array}{l}3.79^{* *} \\
5.11^{* *} \\
1.33\end{array}$ & $\begin{array}{r}116.18 \\
95.58 \\
73.31 \\
96.06 \\
\text { ref }\end{array}$ & $\begin{array}{l}2.13^{*} \\
3.29^{* *} \\
2.55^{*} \\
1.48\end{array}$ & $\begin{array}{r}128.34 \\
43.82 \\
94.04 \\
100.26 \\
\text { ref }\end{array}$ & $\begin{array}{l}1.07 \\
1.10 \\
3.20 \\
3.30\end{array}$ \\
\hline $\begin{array}{l}\text { job tenure squared } \\
\text { primary education } \\
\text { LGSE \& PVE } \\
\text { HGSE \& IVE } \\
\text { HVE } \\
\text { academic education }\end{array}$ & $\begin{array}{c}-0.97 \\
-1.08 \\
0.16 \\
\text { ref } \\
-\end{array}$ & $\begin{array}{c}-2.81^{* *} \\
-3.53^{* *} \\
0.37\end{array}$ & $\begin{array}{l}-2.03 \\
-1.87 \\
-1.16 \\
-2.15 \\
\text { ref }\end{array}$ & $\begin{array}{l}-1.73 \\
-2.58^{* *} \\
-1.55 \\
-1.22\end{array}$ & $\begin{array}{l}-2.02 \\
-0.14 \\
-1.65 \\
-1.00 \\
\text { ref }\end{array}$ & $\begin{array}{l}-0.90 \\
-0.17 \\
-2.26 \\
-1.36\end{array}$ \\
\hline $\begin{array}{l}\text { male } \\
\text { married }\end{array}$ & $\begin{array}{l}279.83 \\
168.00\end{array}$ & $\begin{array}{l}3.70^{* *} \\
2.35^{*}\end{array}$ & $\begin{array}{r}331.99 \\
-19.61\end{array}$ & $\begin{array}{r}2.36 \\
-0.14\end{array}$ & $\begin{array}{r}783.66 \\
59.61\end{array}$ & $\begin{array}{l}5.51^{*} \\
0.48\end{array}$ \\
\hline $\begin{array}{l}\text { industry } \\
\text { agr. \& manufacturing } \\
\text { electr,. gas \& water } \\
\text { construction } \\
\text { trade } \\
\text { transport } \\
\text { private services } \\
\text { other services } \\
\text { large firm } \\
\text { private firm } \\
\text { part-time job } \\
\text { permanent job }\end{array}$ & $\begin{array}{r}\text { g ref } \\
-129.68 \\
-114.17 \\
-122.18 \\
307.53 \\
26.28 \\
-12.08 \\
154.88 \\
-45.78 \\
93.05 \\
199.27\end{array}$ & $\begin{array}{c}-0.36 \\
-1.04 \\
-1.66 \\
3.53^{*} \\
0.19 \\
-0.14 \\
2.80^{* *} \\
-0.52 \\
1.24 \\
2.49^{*}\end{array}$ & $\begin{array}{r}\text { ref } \\
-121.09 \\
-291.94 \\
242.47 \\
-73.83 \\
11.98 \\
-134.70 \\
135.03 \\
-52.02 \\
356.29 \\
-152.42\end{array}$ & $\begin{array}{r}-0.33 \\
-1.41 \\
1.31 \\
-0.29 \\
0.06 \\
-0.77 \\
1.22 \\
-0.34 \\
2.34 \\
-0.89\end{array}$ & $\begin{array}{r}\text { ref } \\
-167.83 \\
-247.80 \\
-11.92 \\
99.26 \\
271.40 \\
-209.01 \\
161.65 \\
-201.33 \\
766.69 \\
-92.14\end{array}$ & $\begin{array}{r}-0.39 \\
-0.90 \\
-0.05 \\
0.34 \\
1.48 \\
-1.18 \\
1.55 \\
-1.49 \\
4.82 \\
-0.46\end{array}$ \\
\hline Adjusted $R^{2}$ & 0.39 & & 0.16 & & 0.24 & \\
\hline $\mathrm{N}$ & 554 & & 820 & & 665 & \\
\hline
\end{tabular}

$=$ significant at $5 \%$-level, ${ }^{* *}=$ significant at $1 \%$-level 
This implies that the additional assumption is made that the skills which the workers with the educational background concerned have are perfectly in alignment with the requirements for the occupation concerned (that is, $M M_{i j}=0$ )

The discussion of these estimation results is split up into four parts: the mismatch measure and the long run wage, job tenure, learning ability and the other determinants of the wage.

\section{The mismatch measure and the long run wage}

The hypotheses with regard to the link between the mismatch measure $M M_{i j}$ and the educational level were shown in figure 3.3. The (absolute value of) the mismatch measure is expected to be a decreasing S-shaped function of the educational level. Figure 6.1 shows the estimation results by occupational level: ${ }^{36}$

\section{Figure 6.1}

The mismatch between occupational and educational levels

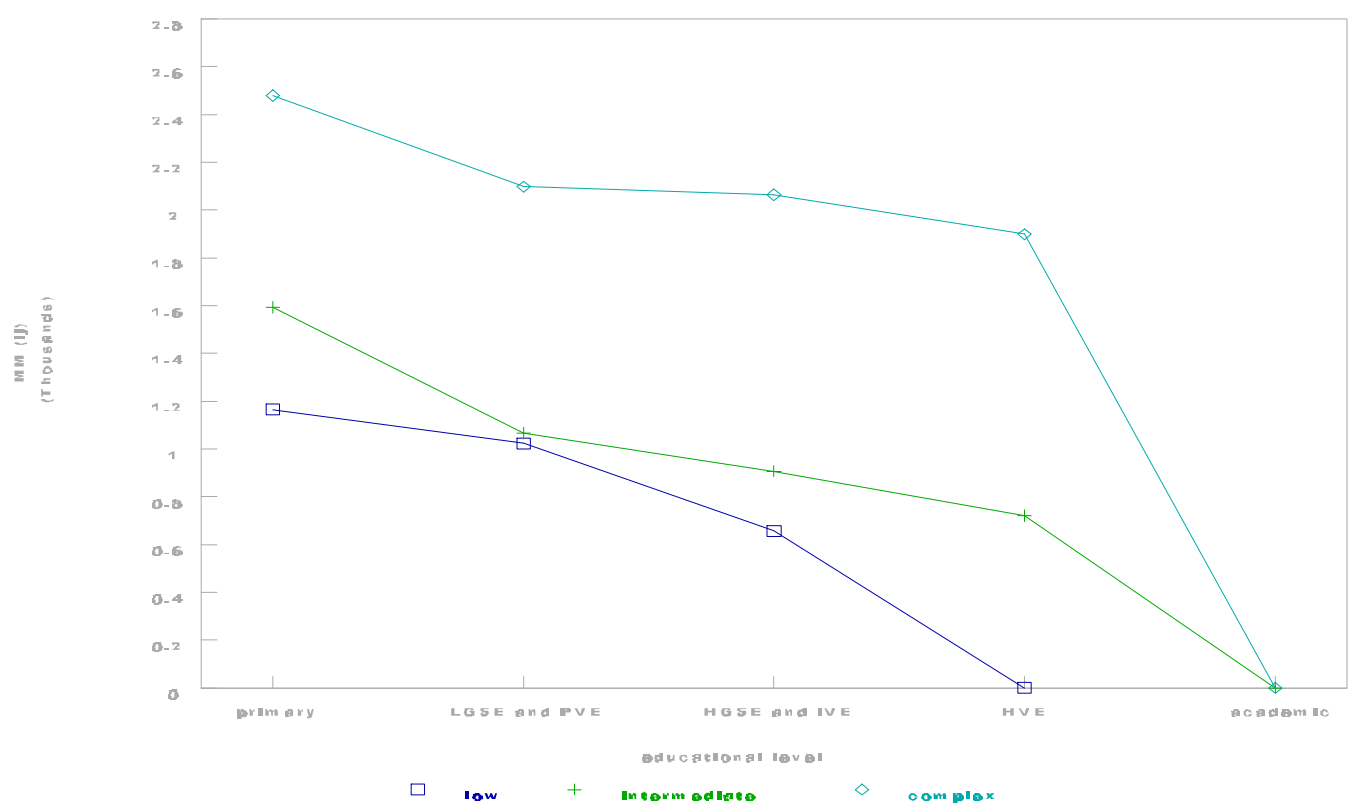

Figure 6.1 shows that the mismatch measure is a decreasing function of the educational level. That is, the higher the educational level, the more the acquired and required skills are in alignment. Furthermore, for every educational level, there is a negative link between the quality of the match and the occupational level. That is, the more complex the job is, the smaller the degree of alignment between acquired and required skills. Table 6.2 shows that almost all the estimates are significant at the $5 \%-l e v e l$. There is one exception: the degree

36. Note that these figures reflect the relative mismatch compared with the reference level. 
of mismatch between primary education and complex jobs is not significant, due to the small number of cases.

Especially with regard to the complex jobs, figure 6.1 also reflects the S-shape of the link between the mismatch measure and the educational level. Remind that the point of inflection of the curve determines the educational level which has a comparative advantage. Figure 6.1 shows clearly that academic graduates have a comparative advantage in complex jobs. With regard to the jobs on a low and an intermediate level the picture is less clear, however. The point of inflection of the curve for low jobs may be around the HGSEand IVE-level, while for the intermediate level the point of inflection may be somewhere around or just above the HVE-level. So, it might be concluded that academic graduates have a comparative advantage in complex jobs, workers with HVE-background at the intermediate job level and workers with a HGSE- or IVE-background in jobs on a low level.

More evidence with regard to the S-shape can be obtained by investigating the significance of differences between mismatches of successive educational levels. With regard to jobs on a low level, only the difference between the mismatch with primary education and LGSE- and PVE is not significant. These findings confirm the statement that the point of inflection of the curve is about the HGSE- and IVE-level. This would imply that HGSE and IVE have a comparative advantage in low jobs. On the intermediate level, no differences between successive educational levels are significant. Table 6.2 shows that the difference between HGSE and IVE on the one hand and academic education is significant. This implies that the point of inflection may be around the HVE-level. Finally, with regard to complex jobs, only the difference between HVE and academic education is significant, which is also an indication for the statement that academic graduates have a comparative advantage in these jobs.

Remind that the intercept can be interpreted as a measure for the wage which is paid if the acquired skills are perfectly in alignment with the requirements. The intercept is in all three equations significantly different from zero. Furthermore, conform the hypothesis, $W_{j}^{p}$ is an increasing function of the job level.

\section{Job tenure}

Earnings are assumed to be an increasing function of job tenure. The estimation results confirm this hypothesis. The parameters reflecting the impact of job tenure on earnings are positive. In seven cases the parameter is significantly positive. Furthermore, the earnings function is expected to be concave. Although less convincing, this hypothesis is confirmed also. Apart from workers having a HGSE- or IVE-background employed in jobs on a low level, the parameter reflecting the concavity of the earnings function is negative. However, only four parameter are significant. It may be concluded that the estimation results are in alignment with one of the basic ideas of the earnings model presented in this paper. The 
quality of the match between the required skills and the acquired skills by means of formal education and job-related training is an increasing function of job tenure. Furthermore, the empirical findings confirm that the productivity increase becomes lower if job tenure increases. In section 6.5 below the assumption that training efforts are the most important factor in explaining these tenure-wage profiles is investigated.

\section{The learning ability index}

Remind that $\theta_{2} /-\theta_{1}$ can be considered to be an estimator for the learning ability index $L A I_{i}$. In section 2 it has been stated that it may be expected that $L A I_{i}$ is positively related to the educational level. Table 6.3 shows the estimation results for the learning ability index.

Table 6.3

The learning ability index

\begin{tabular}{llcc}
\hline educational level & low & $\begin{array}{c}\text { occupational level } \\
\text { intermediate }\end{array}$ & complex \\
\hline primary education & $0.053^{+}$ & $0.073^{+}$ & 0.052 \\
LGSE \& PVE & $0.063^{+}$ & $0.089^{+}$ & 0.021 \\
HGSE \& IVE & 0.035 & $0.081^{+}$ & $0.046^{+}$ \\
HVE & - & 0.133 & $0.053^{+}$ \\
\hline
\end{tabular}

On first sight, these results seem to be rather unsatisfying. However, if the emphasis is on those figures which underlying parameters are both significant the estimates yields quite interesting results. These figures are marked with $\mathrm{a}^{+}$.In the equation concerning jobs on a low level the parameters for primary education and LGSE and PVE are significant. Table 6.3 shows that the learning ability estimate for the LGSE- and PVE-level is higher than for primary education. For jobs on an intermediate level, the picture is less satisfying. The learning ability of workers with a HGSE or IVE-background seems to be lower than for LGSE- and PVE-graduates. Again the learning ability of those who finished primary education is lower than the learning ability of the rest of the workforce. Finally, workers with a HVE-background employed in complex jobs have a higher learning ability than workers with a HGSE- or IVE-background. Two conclusions may be drawn. In the first place, the learning ability of workers who have finished primary education is low compared with the rest of the workforce. In the second place, the learning ability of HVE-graduates is relatively high compared with the rest of the workforce.

\section{Other determinants of the wage}

Both individual and job characteristics are included in the earnings function. With regard to the individual characteristics the empirical results show that the wage for males is significantly higher than for females. This finding confirms the hypothesis. It is also expected that 
being married has a positive effect on earnings. This hypothesis is confirmed for low jobs only.

The empirical results show that the wages do not differ between industries. Only workers employed in the transport industry at the low job level earn a significantly higher wage than workers employed in other industries at the lowest level. There is no significant difference between the private and the public sector also. Furthermore, it is expected that workers employed in a large firm receive higher earnings than workers employed in small firms. Table 6.2 shows that this hypothesis can be confirmed for jobs at the low job level only. ${ }^{37}$ The same conclusion can be drawn with regard to the effect of being permanently employed. Only at the low job level the hypothesis that being permanently employed has a positive effect on earnings can be confirmed. Finally, measured in f.t.e.'s, part-time workers earn significantly more at both the intermediate and the complex job level. This finding can be considered to confirm the notion that having less working hours implies that the (expected) productivity per hour is higher.

\subsection{The earnings function by occupational field}

In section 3 it has been shown that one of the merits of the approach presented in this paper is the possibility to introduce the dimension 'subject' in the analysis. This enables to investigate the degree of alignment between occupations and types of education with a different subject. In appendix 2 is described that, both with regard to occupations and types of education three fields or subjects are distinguished: general and commerce, agricultural and technical and arts and community care. In this subsection the estimation results of the earnings function by occupational field are presented. In contradiction to the analysis by occupational level, the estimates of the mismatch measure are discussed here only, because the results with regard to the other variables do not differ essentially form the analysis presented in table 6.2. The complete estimation results can be found in appendix 3.

The mismatch measure by subject

Table 6.4 shows the estimation results for the mismatch measure $M M_{i j}$ by subject. ${ }^{38,39}$

37. This finding may be interpreted as evidence for the hypothesis that increasing returns to scale especially occur on low job levels.

38. In order to obtain more reliable results, the five educational levels used in the previous analyses have been aggregated. Three educational levels are distinguished: low (primary education), intermediate (LGSE, PVE, HGSE and IVE) and high (HVE and academic education).

39. In table 6.4 the intercept is also shown. Because jobs are aggregated over levels in this analysis, this intercept should be interpreted as the average long run wage for jobs in the occupational field concerned. 
Table 6.4

The mismatch measure by subject

\begin{tabular}{|c|c|c|c|c|c|c|}
\hline \multirow[b]{3}{*}{ type of education } & \multirow{2}{*}{\multicolumn{2}{|c|}{ gen./comm. }} & \multirow{2}{*}{\multicolumn{2}{|c|}{$\begin{array}{c}\text { occupational field } \\
\text { agr./tech. }\end{array}$}} & \multirow{2}{*}{\multicolumn{2}{|c|}{ arts/ care }} \\
\hline & & & & & & \\
\hline & parameter & $\mathrm{t}$-value & parameter & t-value & parameter & t-value \\
\hline intercept & 3187.41 & $4.67^{* *}$ & 2545.26 & $10.87^{* \star}$ & 2781.48 & $12.37^{* *}$ \\
\hline low & -1908.08 & $-1.98^{*}$ & -2298.30 & $-5.37^{* *}$ & -2041.82 & $-6.39^{* *}$ \\
\hline \multicolumn{7}{|l|}{ intermediate } \\
\hline gen./comm. & -1431.34 & $-4.86^{* *}$ & -1114.97 & $-6.53^{* *}$ & -1524.57 & $-8.29^{* *}$ \\
\hline agr./tech. & -1677.12 & $-5.24^{* *}$ & -990.73 & $-4.51^{* *}$ & -1819.54 & $-9.73^{* *}$ \\
\hline arts/comm. care & -1753.25 & $-5.19^{* *}$ & -1520.19 & $-7.61^{* *}$ & -1687.06 & $-8.77^{* *}$ \\
\hline \multicolumn{7}{|l|}{ high } \\
\hline gen./comm. & ref & & ref & & ref & \\
\hline agr./tech. & -273.28 & -0.55 & 544.28 & $2.49^{*}$ & -0.93 & -0.00 \\
\hline arts/comm. care & -420.84 & -0.80 & 47.31 & 0.21 & 128.19 & 0.71 \\
\hline
\end{tabular}

$=$ significant at $5 \%$-level, ${ }^{* \star}=$ significant at $1 \%$-level

Looking at the estimates presented in table 6.4, the following conclusions can be drawn. Workers with a general or commercial educational background are confronted with a lower degree of mismatch in the general and commercial occupational field than other workers. The absolute value of the mismatch measure (1431.34 on the intermediate and 0 , by definition, on the high level) is lower than for other types of education on the same level. The estimates with regard to the technical and agricultural occupations show comparable results concerning workers with a technical or agricultural educational background. The initial wage of these workers is higher than the wage earned by unexperienced workers with a different educational background. In the arts and community care occupational field, the picture is less clear. On the intermediate educational level, the skills acquired by workers with a general or commercial background show relatively the best alignment with the requirements. On the highest level, this is the case for workers graduated from a type of education in the arts and community care sector. Finally, the table shows that, on average, the quality of the match is an increasing function of the educational level. Because the job level is not taken into account, it is not possible here to draw conclusions with regard to the possession of comparative advantage by a particular educational level, however.

Remind that in section 4 it has been stated that, given the educational level, $M M_{i j}$ is expected to be higher if the subject of study is not in alignment with the requirements. 
Therefore, it is useful to analyse the differences between the mismatch measure on a particular educational level. In table 6.5 an overview of these differences is given. ${ }^{40}$

Table 6.5

Differences in the degree of mismatch

\begin{tabular}{|c|c|c|c|c|c|c|}
\hline & gen./c & somm. & $\begin{array}{r}\text { occupational } \\
\text { agr./tect }\end{array}$ & $\begin{array}{l}\text { field } \\
\text { h. }\end{array}$ & arts/ ca & \\
\hline & parameter & t-value & parameter & t-value & parameter & t-value \\
\hline intermediate level & & & & & & \\
\hline$M M_{A T J}-M M_{G C J}$ & -245.78 & $-2.01^{\star}$ & 124.24 & 0.88 & -294.97 & $-3.05^{* *}$ \\
\hline$M M_{A C J}-M M_{G C J}$ & -321.91 & $-2.14^{*}$ & -405.22 & $-3.30^{* *}$ & -162.49 & -1.37 \\
\hline$M M_{A C J}-M M_{A T J}$ & -76.13 & -1.21 & -529.46 & $-2.96^{* *}$ & 132.48 & 1.09 \\
\hline high level & & & & & & \\
\hline$M M_{A T J}-M M_{G C J}$ & -273.28 & -0.55 & 544.28 & $2.49^{*}$ & -0.93 & -0.00 \\
\hline$M M_{A C J}-M M_{G C J}^{G C J}$ & -420.84 & -0.80 & 47.31 & 0.21 & 128.19 & 0.71 \\
\hline$M M_{A C J}-M M_{A T J}^{G}$ & -147.56 & -0.32 & -496.97 & $-1.96^{*}$ & 129.13 & 0.42 \\
\hline
\end{tabular}

In table 6.5 those figures which are most important to analyse the validity of the hypothesis that, if the subject of study is not in alignment with the requirements, $M M_{i j}$ will be higher are printed in italics. ${ }^{41}$ Table 6.5 yields the following conclusions.

The signs of the figures concerning the general and commercial occupations are in alignment with the hypothesis. Both on the intermediate and the high level, the mismatch measure for the general and commercial types of education is lower than for the other types of the education. Unfortunately, the differences are not significant on the high educational level. With regard to the agricultural and technical occupations the evidence which underpins the hypothesis is more convincing. On the high educational level the (unexperienced) workers with a technical or agricultural educational background earn a significantly higher wage. The skills acquired by graduating from these types of education are more in alignment with the requirements than the skills acquired by graduating from the other types of education. On the intermediate educational level, the difference with the types of education dealing with arts and community care is significant only. So, the initial wage for workers with a general or commercial educational background is not significantly lower than for workers who graduated from an agricultural or technical type of education. Finally, three out

40. In table 6.5 the following abbreviations are used:

$\mathrm{GC}=$ general and commercial types of education;

AT $=$ agricultural and technical types of education;

$A C=$ types of education dealing with arts and community care

41. For example, with regard to general and commercial occupations, the difference between the degree of mismatch for agricultural and technical types of education on the one hand and types of education dealing with arts and community care on the other hand is less important. 
of four figures concerning the occupational field 'arts and community care' have a sign which is alignment with the hypothesis. The finding that workers with a general or commercial background yield a higher initial wage than workers who graduated from a type of education dealing with arts and community care has not been expected. Unfortunately, the differences are not significant.

It may be concluded that the figures presented in table 6.5 give some evidence with regard to the validity of the hypothesis that, given the educational level, $M M_{i j}$ is expected to be higher if the subject of study is not in alignment with the requirements. Two remarks have to be made, however. In the first place, the significance level is rather low for the estimates concerning the types of education on the highest educational level. This finding may be due to the small number of respondents who graduated on a high level. In the second place, the significance level for the estimates concerning the general and commercial types of education is rather low. The following explanation may be given for this finding. The occupational sector may include jobs in which management skills are required, which implies that workers with a commercial background are more suited for these jobs. This may also explain the finding that, in the technical occupations, technical graduates do not earn significantly more than commercially educated on the intermediate level. To state it more generally, the aggregation level used here may be too high, which implies that both the occupational and educational classification used here is too heterogeneous to yield reasonable results. Unfortunately, the data set used here is too small to enable to use a lower aggregation level. With this explanation in mind, we have decided to estimate the training function with the results of the analysis by occupational level only.

\subsection{The training cost function}

Section 6.3 has shown that estimating the earnings function by occupational level yields results which are in alignment with the model described in this paper. The estimates have shown that the degree of mismatch is a decreasing function of the educational level. Furthermore, for each occupational level the model enables to find the educational level which has a comparative advantage. Finally, the estimates confirm the hypothesis that earnings are an increasing, concave function of job tenure.

Estimating the training cost function (4.8) enables to investigate the validity of the theoretical framework described in section 2. Before the estimation results are presented, a few remarks have to be made. In the first place, remind that, due to data limitations, the choice has been made to use a dummy variable as dependent variable in the training equation. $A$ distinction is made between those workers who receive training and those who do not. Furthermore, it should be noted that the mismatch measure estimates presented in table 6.2 and figure 6.1 are used to estimate the training function. In the third place, the squared job tenure is removed because there is a high correlation between the variables $M M_{i j} t$ and 
$\hat{M M}{ }_{i j} t^{2}{ }^{42}$ Finally, making the parameters both occupation- and type of education specific, did not yield significantly better results. This implies that differences in the effect of job tenure on training is determined by the mismatch measure only. Therefore, one aggregated training equation is estimated.

The assumption is made that the probability to receive training $P_{t r}$ can be estimated by means of the following binomial logit model (6.2):

$$
\left(P_{t r}\right)_{h i j}=\frac{e^{\mu+X_{h} \eta+\phi_{1} M M_{i j}+\phi_{2} M M_{i j} t}}{1+e^{\mu+X_{h} \eta+\phi_{1} M M_{i j}+\phi_{2} M M_{i j} t}}
$$

The estimation results, which are obtained by means of Maximum Likelihood are shown in table 6.6.

Table 6.6

The probability to receive training

\begin{tabular}{|c|c|c|}
\hline variable & parameter & Wald-statistic \\
\hline intęrcept & -1.31 & $11.60^{* *}$ \\
\hline$M M_{i j} / 1000$ & 0.41 & $8.87^{* *}$ \\
\hline $\mathrm{MM}_{i j}^{\prime \prime}{ }^{*}$ job tenure / 1000 & -0.01 & $11.04^{* *}$ \\
\hline male $^{\prime \prime}$ & -0.19 & 1.41 \\
\hline married & 0.14 & 0.91 \\
\hline \multicolumn{3}{|l|}{ industry } \\
\hline agriculture and manufacturing & ref & \\
\hline electricity, gas and water & 0.42 & 0.99 \\
\hline construction & 0.48 & 3.15 \\
\hline trade & 0.14 & 0.51 \\
\hline transport & 0.40 & 2.37 \\
\hline private services & 0.21 & 0.83 \\
\hline other services & 0.20 & 0.93 \\
\hline large firm & 0.11 & 0.61 \\
\hline private firm & -0.20 & 1.50 \\
\hline part-time job & -0.47 & $7.44^{* *}$ \\
\hline permanent job & 0.72 & $9.91^{* *}$ \\
\hline -2 Log Likelihood & 1658.61 & \\
\hline
\end{tabular}

Table 6.6 shows that the estimated degree of mismatch $\hat{M M_{i j}}$ between the occupational and educational level concerned has a significant positive effect on the probability to

42. The correlation is equal to 0.95 . 
receive training. ${ }^{43}$ This finding is in alignment with the theoretical framework. The greater the gap between acquired and required skills, the more job-related training is required to bring the worker concerned on the long-run productivity level.

Secondly, the table shows that the probability to receive training slightly decreases with job tenure. This parameter is significant also. This estimated effect of job tenure on the probability to receive training, is also in accordance with the theoretical framework. There is an incentive for both firms and workers to concentrate the training efforts immediately after the recruitment. However, in order to enable a worker to benefit from learning-by-doing also, the training efforts will not take all at once. This results in a training pattern in which training efforts decrease with job tenure.

The individual characteristics, gender and martial status, do not have a significant impact on the probability to receive training. This implies that the positive effect of being male on the wage found in table 6.2 can not be explained by means of a higher probability to receive training. This finding also that the hypotheses formulated in section 4.4 can not be confirmed. With regard to the job characteristics included, the following conclusions can be drawn. In the first place, there are no significant differences between the industries. This finding is in alignment with the earnings function presented in table 6.2, which shows that earnings do not differ between industries also. The same conclusion can be drawn with regard to the distinction between the private and the public sector. Being employed in a large firm has an effect neither, which is also in alignment with the earnings function estimates. Being part-time and temporary employed both have a negative effect. Both results are in alignment with the hypotheses formulated in section 4.4. Being temporarily or part-time employed implies a higher turnover rate, which may result in a lower probability to receive training.

It may be concluded that the training data confirm the theoretical framework presented in this paper. The probability to receive training is an increasing function of the mismatch between the occupational level on which a worker is employed and the level of the worker's educational background. Furthermore, job tenure has a negative effect on the probability to receive training.

\section{Conclusions}

In this paper a model has been developed which fits in the job matching tradition. Earnings are assumed to be related to both the educational background of the worker and the job in which the worker concerned is employed. The aim of the paper has been twofold. In the

43. The significance has been calculated by means of the Wald-statistic, which is, for a parameter $\beta_{i}$, equal to $\hat{\beta}_{i}^{2} / \hat{\sigma}_{\hat{\beta}_{i}}^{2}$, which has a $X^{2}$-distribution. 
first place, to find an explanation for the mismatch phenomena which can be found on the labour market. By emphasising the nontransparency of the labour market, a theoretical framework has been developed in which a firm faces a trade-off between search and training costs. As a result a profit-maximising firm may decide to hire a worker whose skills are not in alignment with the required skills. Job-related training is required to enable the worker to achieve a satisfying productivity level.

Applying this theoretical framework has three important implications. In the first place, training costs are assumed to be positively related to the degree of mismatch between required and acquired skills. In the second place, it is possible to derive the well-known concave earnings-tenure profiles. Finally, the estimated initial wage in an earnings-tenureprofile can be interpreted as a measure for the quality of the match between acquired and required skill. This brings us by the second aim the paper. By estimating earnings-tenure profiles by occupation an endogenous measure is created, which enables to investigate the quality of the match between occupations and types of education and to find that particular type of education which has a comparative advantage in the occupation concerned.

By estimating earnings function by occupational level and occupational field the theoretical framework has been tested empirically. The hypothesis that the earnings-tenure profile is concave can be confirmed by the estimates. Furthermore, the estimates of the mismatch measure yield attractive results, especially concerning the quality of the match between occupational and educational levels. Finally, estimating a training function confirms the hypothesis that training efforts are positively related to the degree of mismatch. So, it may be concluded that the approach which has been developed in this paper yields a useful mismatch measure.

The approach developed here has some attractive features. In the first place, concerning the mismatch measure, the approach enables to determine both the character and the degree of mismatch endogenously. In the second place, from a theoretical point of view, it is relatively easy to introduce the dimension 'subject' into the analysis. These are important differences with previous rate of return studies, which focus on the level and determine he optimal level exogenously. Furthermore, the mismatch measure has the attractive feature that it is cardinal.

On the other hand, the approach also causes a few problems. The data requirements are relatively high. Therefore, we have decided to use a high aggregation level in this paper. With regard to the analysis by occupational level, this still yields interesting results. Especially with regard to the analysis by subject, however, the informative value of the analysis is relatively low. More detailed data sets are required to obtain useful information regarding the quality of the match between specific occupations and types of education. 


\section{References}

Allaart P.C., Kunnen R., Praat W.C.M., De Voogd-Hamelink A.M. and Vosse J.P.M. (1993), Trendrapport Aanbod van Arbeid 1993, OSA report OSA17, Den Haag.

Becker G.S. (1964), Human Capital, a Theoretical and Empirical Analysis with Special Reference to Education, NBER, New York.

Cohn E. and Khan S.P. (1995), 'The wage effects of overschooling revisited', Labour Economics, vol. 2, pp. 67-76.

Ehrenberg R.G. and Smith R.S. (1994), Modern Labor Economics; Theory and Public Policy, Harper Collins College Publishers, New York, 5th edition.

Freeman R.B. (1976), The Overeducated American, New York Academic Press, New York. Gelderblom A., 't Hoen N.B.J.G. and De Koning J. (1994), Wat Wordt Men Wijzer van Onderwijs?, OSA Working Paper W119, Den Haag.

Groot W. and Maassen-van den Brink H. (1996), 'Overscholing en verdringing op de arbeidsmarkt', Economisch Statistische Berichten, vol. 81, no. 4042, pp. 74-77.

Hartog J. (1985), 'Earnings Functions; Testing for the Demand Side', Economics Letters, vol. 19, pp. 281-285.

Hartog J. (1992), Capabilities, Allocation and Earnings, Kluwer Academic Publishers, Boston, Dordrecht, London.

Hartog J. and Oosterbeek H. (1988), 'Education, Allocation and Earnings in the Netherlands: $\quad$ Overschooling?, Economics of Education Review, vol. 7, no. 2, pp. 185-194. Howitt P. (1988), 'Business Cycles and Costly Search and Recruiting', Quarterly Journal of Economics, vol. 103, February, pp. 147-166.

Jovanovic B. (1979), 'Job Matching and the Theory of Turnover', Journal of Political Eco nomy, vol. 87, no. 5, pp. 972-990.

Layard R., Nickell S. and Jackman R. (1991), Unemployment: Macroeconomic Performance and the Labour Market, Oxford University Press, Oxford.

Mincer J. (1974), Schooling, Experience and Earnings, NBER, New York.

Mincer J. (1989), 'Human Capital and the Labor Market: A Review of Current Research', Educational Researcher, vol. 18, no. 5, pp. 27-34, reprinted in: Blaug M. (ed) (1992), The Economic Value of Education, Edward Elgar Publishing, Aldershot.

Oosterbeek H. and Webbink D. (1996), 'Over scholing, overscholing en inkomen', Economisch Statistische Berichten, vol. 81, no. 4049, pp. 240-241.

Psacharopoulos G. (1987), 'Earnings functions', in: Psacharopoulos G. (ed), Economics of Education; Research and Studies, Pergamon Press, Oxford.

Research Centre for Education and the Labour Market (1993), The Labour Market by Education and Occupation to 1998, ROA-R-1993/10E, Maastricht.

Sattinger M. (1975), 'Comparative Advantage and the Distributions of Earnings', Econometrica, vol. 43, no. 3, pp. 455-468. 
Sattinger M. (1993), 'Assignment Models of the Distribution of Earnings', Journal of Eco nomic Literature, vol. 31, June, pp. 831-880.

Sicherman N. (1991), 'Overschooling in the Labor Market', Journal of Labor Economics, vol. 9, no. 2, pp. 101-122.

Sloane P.J., Battu H. and Seaman P.T. (1995), Overeducation, Undereducation and the British Labour Market, Paper presented at the 7th Annual EALE-conference, September 7-10, 1995, Lyon.

Thurow L.C. (1975), Generating Inequality, Basic Books, New York.

Tinbergen J. (1956), 'On the Theory of Income Distribution', Weltwirtschaftliches Archiv, vol. 77, no. 2, pp. 155-175.

Van de Loo P.J.E, Hoevenberg J. and Van der Velden R.K.W. (1995), De

Arbeidsmarktpositie van Afgestudeerden van het Hoger Beroepsonderwijs: HBO-monitor 1994, HBO-Raad, Den Haag.

Van Smoorenburg M.S.M. and Van der Velden R.K.W. (1995), Training en Beloning van Schoolverlaters, Paper presented at the 'Onderwijs Research Dagen, June 19-21, 1995, Groningen.

Willis R.J. (1986), 'Wage Determinants: A Survey and Reinterpretation of Human Capital Earnings Functions', in: Ashenfelter O. and Layard R. (eds), Handbook of Labor Economics, vol. 1, North Holland, Amsterdam. 


\section{Appendix 1 Derivation of the Taylor approximations}

Taylor's theorem states that a function $f(x)$ can be approximated about $x=a$ by means of the following infinite power series:

$$
\sum_{k=0}^{4} \frac{f^{k}(a)}{k !}(x-a)^{k}=f(a)+f^{\prime}(a) \frac{x-a}{1 !}+f^{\prime \prime}(a) \frac{(x-a)^{2}}{2 !}+f^{\prime \prime \prime}(a) \frac{(x-a)^{3}}{3 !}+\cdots
$$

In this paper Taylor's theorem is applied to both the earnings function (4.1) and the training cost function (4.5).

The earnings function looks as follows:

$$
W_{h i j, t}=W_{j}^{p}+X_{h j} \beta-M M_{i j} e^{-L A l_{i} t}
$$

In order to obtain a second order power series which can be used as an approximation of the earnings function about $t=0, W_{h i j, 0}$ and the first and the second derivative for $t=0$ have to be calculated:

$$
\begin{aligned}
& W_{h i j, 0}=W_{j}^{p}+X_{h j} \beta-M M_{i j} \\
& W_{h i j, 0}^{\prime}=L A I_{i} M M_{i j} e^{-L A l_{i} @ 0}=L A I_{i} M M_{i j} \\
& W_{h i j, 0}^{\prime \prime}=-L A l_{i}^{2} M M_{i j} e^{-L A l_{i} @ 0}=-L A l_{i}^{2} M M_{i j}
\end{aligned}
$$

Substituting (A.3), (A.4) and (A.5) into (A.1) yields:

$$
W_{h i j, t}=W_{j}^{p}+X_{h j} \beta-M M_{i j}+L A I_{i} M M_{i j} t-\frac{1}{2} L A l_{i}^{2} M M_{i j} t^{2}+R_{2}
$$

in which $R_{2}$ are the elements of the infinite series (A.1) which are not taken into account. Equation (A.6) is similar to equation (4.2).

The training cost function looks as follows:

$$
C_{h i j, t}=\mu_{j}+X_{h j} \eta+C_{i j, 0} e^{-L A l_{i} t}
$$

In order to obtain a second order power series which can be used as an approximation of the training cost function about $t=0, C_{h i j, 0}$ and the first and the second derivative for $t=0$ have to be calculated:

$$
C_{h i j, 0}=\mu_{j}+X_{h j} \eta+C_{i j, 0}
$$




$$
\begin{aligned}
& C^{\prime}{ }_{h i, t}=-L A l_{i} C_{i j, 0} e^{-L A l_{i} @ 0}=-L A l_{i} C_{i j, 0} \\
& C^{\prime \prime}{ }_{h i j, t}=L A l_{i}^{2} C_{i j, 0} e^{-L A l_{i} @ 0}=L A l_{i}^{2} C_{i j, 0}
\end{aligned}
$$

Substituting (A.8), (A.9) and (A.10) into (A.1) yields:

$$
C_{h i j, t}=\mu_{j}+X_{h j} \eta+C_{i j, 0}-L A l_{i} C_{i j, 0} t+\frac{1}{2} L A l_{i}^{2} C_{i j, 0} t^{2}+R_{2}
$$

which is similar to equation (4.6). 


\section{Appendix 2 Classifications}

In this paper 7 industries are distinguished:

1. agriculture and manufacturing;

2. electricity, gas and water;

3. construction;

4. trade;

5. transport;

6. private services;

7. other services;

There are 7 occupational levels which can be described as follows:

1. unskilled occupations;

2. skilled occupations with requirements on a low level;

3,4 skilled jobs with requirements on a intermediate level. Level 4 requires more practical experience

$5,6,7 \quad$ highly skilled jobs. Requirements vary from complex to theoretical knowledge on an academic level

These 7 levels are aggregated to obtain three categories: jobs on a low level (level 1 and 2), jobs on a intermediate level (level 3 and 4) and complex jobs (level 5,6, and 7).

Ten occupational sectors are distinguished:

$0 . \quad$ educational occupations;

1. cultural occupations;

2. agricultural occupations;

3. technical and industrial occupations;

4. transport occupations;

5. medical and paramedical occupations;

6. commercial and administrative occupations;

7. socio-cultural occupations;

8. hotel, catering and service occupations;

9. public security and safety occupations.

These sectors are aggregated to obtain three categories which are based on the educational classification described below: general and commercial occupations (sector 0,4 and 6 ), agricultural and technical occupations (sector 2 and 3) and, finally, occupations in arts and community care (sectors 1,5,7,8 and 9). 
The educational classification is based on the SOI 1978, in which 6 educational levels are distinguished. In this paper the respondents with the lowest educational background (no education) are excluded from the analysis. The educational classification looks as follows:

2. primary education;

3. lower general secondary education (LGSE) and preparatory vocational education (PVE);

- general and commerce;

- technical and agricultural;

- community care;

4. higher general secondary education (HGSE) and intermediate vocational education (IVE);

- general;

- technical and agricultural;

- commerce;

- community care;

5. higher vocational education (HVE);

- commerce;

- technical and agricultural;

- arts and community services;

6. academic education;

- commerce;

- technical and agricultural;

- arts and community services. 


\section{Appendix 3 Tenure-earnings profiles by occupational field (net monthly wages in f.t.e. in dutch guilders)}

\begin{tabular}{|c|c|c|c|c|c|c|}
\hline \multirow[b]{2}{*}{ variable } & \multicolumn{2}{|c|}{ gen./comm. } & \multicolumn{2}{|c|}{$\begin{array}{c}\text { occupational field } \\
\text { agr./tech. }\end{array}$} & \multicolumn{2}{|c|}{ arts/ care } \\
\hline & parameter & $\mathrm{t}$-value & parameter & t-value & parameter & t-value \\
\hline intercept & 3187.41 & $4.67^{* *}$ & 2545.26 & $10.87^{* *}$ & 2781.48 & $12.37^{\star \star}$ \\
\hline \multicolumn{7}{|l|}{ type of education } \\
\hline $\begin{array}{l}\text { low } \\
\text { intermediate }\end{array}$ & -1908.08 & $-1.98^{*}$ & -2298.30 & $-5.37^{* *}$ & -2041.82 & $-6.39^{* *}$ \\
\hline gen./comm. & -1431.34 & $-4.86^{* *}$ & -1114.97 & $-6.53^{* *}$ & -1524.57 & $-8.29^{* *}$ \\
\hline agr./tech. & -1677.12 & $-5.24^{* *}$ & -990.73 & $-4.51^{\star *}$ & -1819.54 & $-9.73^{\star *}$ \\
\hline $\begin{array}{l}\text { arts/comm. care - } \\
\text { high }\end{array}$ & -1753.25 & $-5.19^{* *}$ & -1520.19 & $-7.61^{* *}$ & -1687.06 & $-8.77^{* *}$ \\
\hline gen./comm. & ref & & ref & & ref & \\
\hline agr./tech. & -273.28 & -0.55 & 544.28 & $2.49^{*}$ & -0.93 & -0.00 \\
\hline arts/comm. care & -420.84 & -0.80 & 47.31 & 0.21 & 128.19 & 0.71 \\
\hline \multicolumn{7}{|l|}{ job tenure } \\
\hline low & 51.93 & 0.52 & 137.10 & $3.48^{* *}$ & 72.92 & $2.63^{* *}$ \\
\hline $\begin{array}{l}\text { intermediate } \\
\text { high }\end{array}$ & $\begin{array}{l}96.50 \\
\text { ref }\end{array}$ & $2.61^{* *}$ & $\begin{array}{l}46.09 \\
\text { ref }\end{array}$ & $3.17^{\star *}$ & $\begin{array}{l}62.24 \\
\text { ref }\end{array}$ & $4.39^{* *}$ \\
\hline \multicolumn{7}{|l|}{ job tenure squared } \\
\hline low & -0.31 & -0.14 & -2.04 & $-2.32^{*}$ & -1.30 & $-2.26^{*}$ \\
\hline intermediate & -1.45 & -1.59 & -0.18 & -1.32 & -1.02 & $-2.95^{* *}$ \\
\hline high & ref & & ref & & ref & \\
\hline male & 493.61 & 1.73 & 748.25 & $7.87^{* *}$ & 719.19 & $6.92^{* *}$ \\
\hline married & -85.44 & -0.36 & 124.93 & 1.41 & 219.59 & 2.61 \\
\hline \multicolumn{7}{|l|}{ industry } \\
\hline agr. \& manufacturing & $g$ ref & & ref & & ref & \\
\hline electr,. gas \& water & 6.13 & 0.01 & 61.51 & 0.22 & 144.49 & 0.51 \\
\hline construction & -224.13 & -0.39 & -27.10 & -0.11 & -138.83 & -1.61 \\
\hline trade & 38.67 & 0.13 & -136.27 & -1.02 & -130.16 & -1.13 \\
\hline transport & 443.39 & 0.66 & -358.76 & $-2.64^{* *}$ & 104.88 & 0.73 \\
\hline private services & 550.84 & 1.52 & -105.73 & -0.90 & 253.99 & 1.26 \\
\hline other services & 17.19 & 0.05 & -36.80 & -0.29 & -79.88 & -0.70 \\
\hline large firm & 322.17 & 1.47 & 23.27 & 0.31 & 124.22 & 1.82 \\
\hline private firm & -25.12 & -0.10 & 10.02 & 0.10 & -316.88 & $-3.26^{* *}$ \\
\hline part-time job & 496.70 & 1.80 & 19.58 & 0.20 & 456.87 & $4.77^{\star \star}$ \\
\hline permanent job & -501.48 & -1.65 & 291.94 & $2.44^{*}$ & 190.43 & 1.72 \\
\hline Adjusted $R^{2}$ & 0.12 & & 0.41 & & 0.29 & \\
\hline $\mathrm{N}$ & 474 & & 556 & & 1009 & \\
\hline
\end{tabular}

